\title{
2 CRISPR-based Crop Improvements: A Way Forward to Achieve Zero Hunger
}

3 Shakeel Ahmad ${ }^{1,2, \dagger}$, Liqun Tang ${ }^{1, \dagger}$, Rahil Shahzad ${ }^{3}$, Amos Musyoki Mawia ${ }^{1}$, Gundra

4 Sivakrishna Rao ${ }^{4}$, Shakra Jamil ${ }^{3}$, Chen $\mathrm{Wei}^{1}$, Zhonghua Sheng ${ }^{1}$, Gaoneng Shao ${ }^{1}$, Xiangjin

$5 \mathrm{Wei}^{1}$, Peisong $\mathrm{Hu}^{1}$, Magdy M. Mahfouz ${ }^{4}$, Shikai $\mathrm{Hu}^{1, *}$, and Shaoqing Tang ${ }^{1, *}$

$6 \quad{ }^{1}$ State Key Laboratory of Rice Biology, China National Center for Rice Improvement, China

$7 \quad$ National Rice Research Institute, Hangzhou 310006, China.

$8 \quad{ }^{2}$ Maize Research Station, Ayub Agricultural Research Institute, Faisalabad 38000, Pakistan.

$9{ }^{3}$ Agricultural Biotechnology Research Institute, Ayub Agricultural Research Institute, 10 Faisalabad, Pakistan.

$11{ }^{4}$ Laboratory for Genome Engineering and Synthetic Biology, Division of Biological Sciences, 124700 King Abdullah University of Science and Technology, Thuwal 23955-6900, Saudi 13 Arabia.

\section{*Corresponding authors:}

15 Shaoqing Tang, Ph.D. \& Professor, China National Rice Research Institute (CNRRI), No.359

16 Tiyuchang Road, Hangzhou 310006, P. R. China, tangshaoqing@ caas.cn.

17 Shikai Hu, Ph.D. \& Professor, China National Rice Research Institute (CNRRI), No.359

18 Tiyuchang Road, Hangzhou 310006, P. R. China, hushikai@ caas.cn.

19 †These authors have contributed equally. 


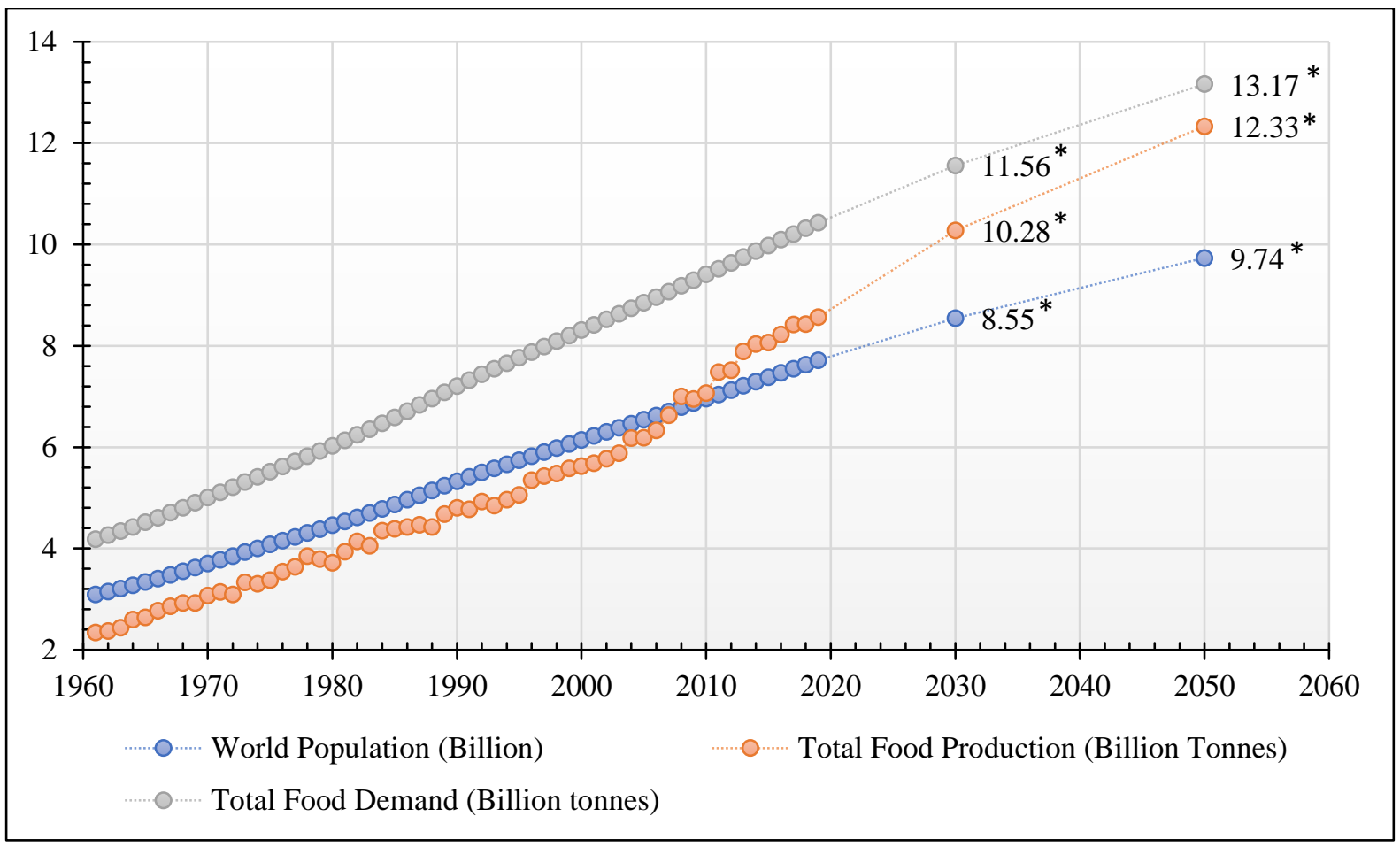

Fig. S1. World population and crop-based world food production since 1961. Year-wise aggregate of cereals, roots and tubers, pulses and legumes, tree nuts, fruits and vegetables, sugar crops, and oil crops. ${ }^{1}$

\section{* Projected values. Source: ${ }^{1}$}

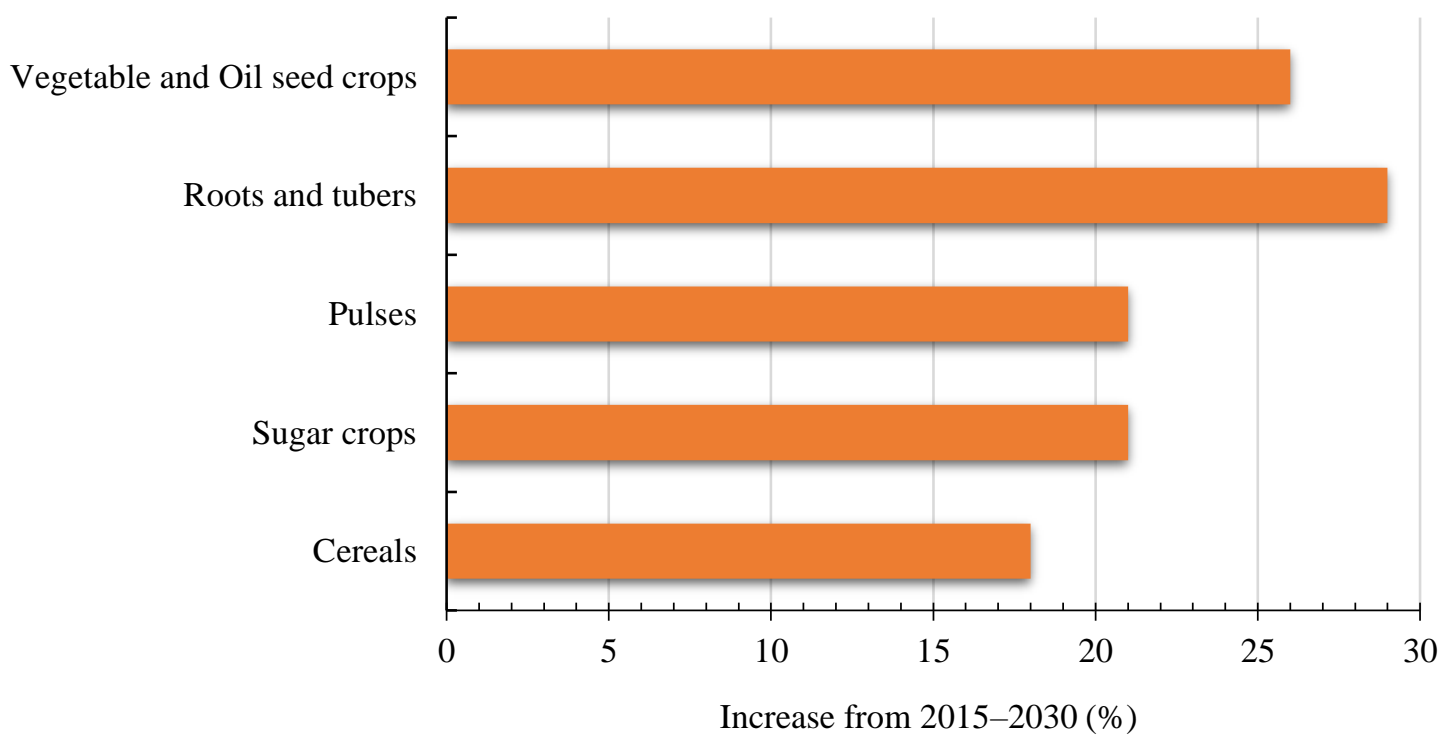

${ }^{1}$ Projected value of food demand in 2030 is calculated at the rate of $35 \%$ more food required than produced in 2019 (Source; FAO). According to current trends of food production and demand, the world can still face food shortages in 2030 and 2050. The difference between food demand and production can be filled by developing new and high yielding crop varieties by using different new breeding technologies, bringing innovations, and public and private partnerships. 
26 Fig. S2. Projected change in the demand for food production between 2015 and 2030.

27 Estimated world food demand for cereals, roots and tubers, pulses, sugar, vegetables, and oil seed crops.

Source: ${ }^{1}$

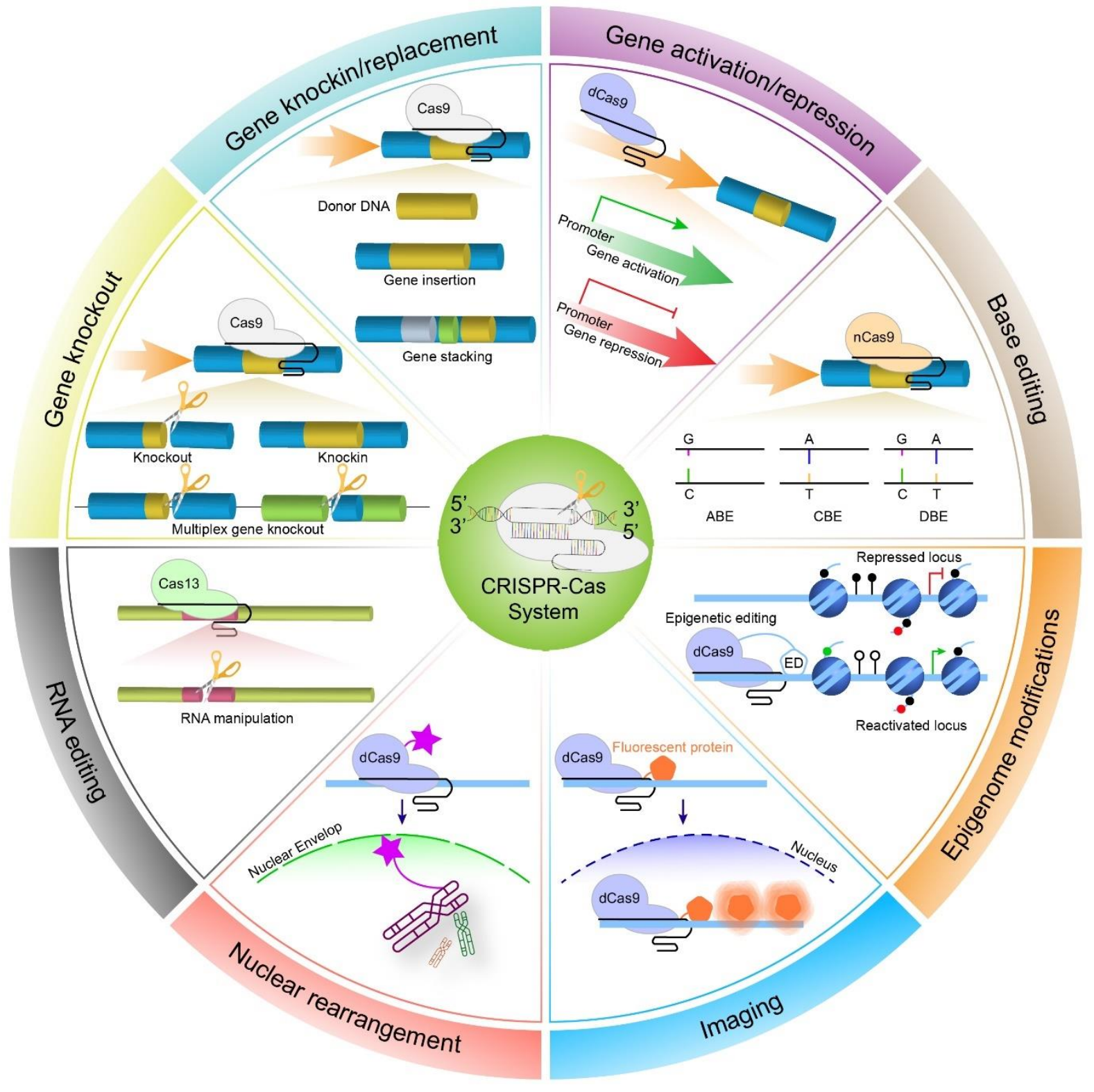

32 Figure S3: Applications of CRISPR-Cas systems in genome modifications. 
Table S1. Role of the CRISPR-Cas system in development of disease-resistant food crops

\begin{tabular}{|c|c|c|c|c|c|c|c|}
\hline $\begin{array}{l}\text { Food Crop } \\
\text { Species }\end{array}$ & Biotic stress & $\begin{array}{l}\text { Targeted } \\
\text { gene/s }\end{array}$ & $\begin{array}{l}\text { Gene } \\
\text { function }\end{array}$ & System & $\begin{array}{l}\text { Transgene- } \\
\text { free Plants }\end{array}$ & Outcome & Reference \\
\hline \multirow{8}{*}{ Rice } & $\begin{array}{l}\text { Bacterial } \\
\text { blight }\end{array}$ & $\begin{array}{l}\text { Xa13 / Host S- } \\
\text { gene }\end{array}$ & $\begin{array}{l}\text { Disease } \\
\text { facilitation }\end{array}$ & $\begin{array}{l}\text { CRISPR- } \\
\text { Cas9 }\end{array}$ & YES & $\begin{array}{l}\text { Resistant } \\
\text { plants }\end{array}$ & 2 \\
\hline & $\begin{array}{l}\text { Bacterial } \\
\text { blight }\end{array}$ & $\begin{array}{l}\text { OsSWEET13 / } \\
\text { Host S-gene }\end{array}$ & $\begin{array}{l}\text { Disease } \\
\text { facilitation }\end{array}$ & $\begin{array}{l}\text { CRISPR- } \\
\text { Cas9 }\end{array}$ & $\mathrm{NO}$ & $\begin{array}{l}\text { Resistant } \\
\text { plants }\end{array}$ & 3 \\
\hline & $\begin{array}{l}\text { Bacterial } \\
\text { blight }\end{array}$ & $\begin{array}{l}\text { OsSWEET14 / } \\
\text { Host S-gene }\end{array}$ & $\begin{array}{l}\text { Disease } \\
\text { facilitation }\end{array}$ & $\begin{array}{l}\text { CRISPR- } \\
\text { Cas9 }\end{array}$ & YES & $\begin{array}{l}\text { Resistant } \\
\text { plants }\end{array}$ & 4,5 \\
\hline & Rice blast & $\begin{array}{l}\text { OsERF922 / } \\
\text { Host S-gene }\end{array}$ & $\begin{array}{l}\text { Disease } \\
\text { facilitation }\end{array}$ & $\begin{array}{l}\text { CRISPR- } \\
\text { Cas9 }\end{array}$ & YES & $\begin{array}{l}\text { Resistant } \\
\text { plants }\end{array}$ & 6 \\
\hline & Rice blast & $\begin{array}{l}\text { Pi21 / Host S- } \\
\text { gene }\end{array}$ & $\begin{array}{l}\text { Disease } \\
\text { facilitation }\end{array}$ & $\begin{array}{l}\text { CRISPR- } \\
\text { Cas9 }\end{array}$ & YES & $\begin{array}{l}\text { Resistant } \\
\text { plants }\end{array}$ & 7,8 \\
\hline & Rice blast & $\begin{array}{l}A L B 1, \quad R S Y 1 / \\
\text { Fungal gene }\end{array}$ & $\begin{array}{l}\text { Facilitate } \\
\text { pathogen } \\
\text { growth }\end{array}$ & $\begin{array}{l}\text { CRISPR- } \\
\text { Cas9 }\end{array}$ & YES & $\begin{array}{l}\text { Improved } \\
\text { resistance }\end{array}$ & 9 \\
\hline & False smut & $\begin{array}{l}\text { USTA, } \\
\text { UvSLT2/ } \\
\text { Fungal gene }\end{array}$ & $\begin{array}{l}\text { Facilitate } \\
\text { pathogen } \\
\text { growth }\end{array}$ & $\begin{array}{l}\text { CRISPR- } \\
\text { Cas9 }\end{array}$ & YES & $\begin{array}{l}\text { Improved } \\
\text { resistance }\end{array}$ & 10 \\
\hline & $\begin{array}{l}\text { Rice tungro } \\
\text { disease }\end{array}$ & $e I F 4 G$ & $\begin{array}{l}\text { Disease } \\
\text { facilitation }\end{array}$ & $\begin{array}{l}\text { CRISPR- } \\
\text { Cas9 }\end{array}$ & YES & $\begin{array}{l}\text { Resistant } \\
\text { plants }\end{array}$ & 11 \\
\hline
\end{tabular}




\begin{tabular}{|c|c|c|c|c|c|c|c|}
\hline \multirow{2}{*}{ Wheat } & $\begin{array}{l}\text { Powdery } \\
\text { mildew }\end{array}$ & $\begin{array}{l}\text { TaMLO / Host } \\
\text { S-gene }\end{array}$ & $\begin{array}{l}\text { Disease } \\
\text { facilitation }\end{array}$ & $\begin{array}{l}\text { CRISPR- } \\
\text { Cas9 }\end{array}$ & YES & $\begin{array}{l}\text { Resistant } \\
\text { plants }\end{array}$ & 12 \\
\hline & $\begin{array}{l}\text { Powdery } \\
\text { mildew }\end{array}$ & $\begin{array}{l}\text { TaEDRl / Host } \\
\text { S-gene }\end{array}$ & $\begin{array}{l}\text { Disease } \\
\text { facilitation }\end{array}$ & $\begin{array}{l}\text { CRISPR- } \\
\text { Cas9 }\end{array}$ & NO & $\begin{array}{l}\text { Resistant } \\
\text { plants }\end{array}$ & 13 \\
\hline Barley & $\begin{array}{ll}\text { DNA viral } \\
\text { disease }\end{array}$ & $\begin{array}{l}\text { MP, CP, } \\
\text { Rep/Rep, IR / } \\
\text { Virus genome }\end{array}$ & Virus spread & $\begin{array}{l}\text { CRISPR- } \\
\text { Cas9 }\end{array}$ & NO & $\begin{array}{l}\text { Resistant } \\
\text { plants }\end{array}$ & 14 \\
\hline \multirow{7}{*}{ Tomato } & $\begin{array}{l}\text { Bacterial } \\
\text { speck }\end{array}$ & $\begin{array}{l}\text { SIDMR6-1 } \\
\text { Host S-gene }\end{array}$ & $\begin{array}{l}\text { Disease } \\
\text { facilitation }\end{array}$ & $\begin{array}{l}\text { CRISPR- } \\
\text { Cas9 }\end{array}$ & NO & $\begin{array}{l}\text { Resistant } \\
\text { plants }\end{array}$ & 15 \\
\hline & $\begin{array}{l}\text { Phytophthora } \\
\text { blight }\end{array}$ & $\begin{array}{l}\text { SIDMR6-1 } \\
\text { Host S-gene }\end{array}$ & $\begin{array}{l}\text { Disease } \\
\text { facilitation }\end{array}$ & $\begin{array}{l}\text { CRISPR- } \\
\text { Cas9 }\end{array}$ & NO & $\begin{array}{l}\text { Resistant } \\
\text { plants }\end{array}$ & \multirow{3}{*}{16} \\
\hline & $\begin{array}{l}\text { Bacterial } \\
\text { spot }\end{array}$ & $\begin{array}{l}\text { SIDMR6-1 } \\
\text { Host S-gene }\end{array}$ & $\begin{array}{l}\text { Disease } \\
\text { facilitation }\end{array}$ & $\begin{array}{l}\text { CRISPR- } \\
\text { Cas9 }\end{array}$ & NO & $\begin{array}{l}\text { Resistant } \\
\text { plants }\end{array}$ & \\
\hline & $\begin{array}{l}\text { Bacterial } \\
\text { speck }\end{array}$ & $\begin{array}{l}\text { SlJAZ2 / Host } \\
\text { S-gene }\end{array}$ & $\begin{array}{l}\text { Disease } \\
\text { facilitation }\end{array}$ & $\begin{array}{l}\text { CRISPR- } \\
\text { Cas9 }\end{array}$ & n.d & $\begin{array}{l}\text { Resistant } \\
\text { plants }\end{array}$ & \\
\hline & $\begin{array}{l}\text { Powdery } \\
\text { mildew }\end{array}$ & $\begin{array}{l}\text { SlMlo1 / Host } \\
\text { S-gene }\end{array}$ & $\begin{array}{l}\text { Disease } \\
\text { facilitation }\end{array}$ & $\begin{array}{l}\text { CRISPR- } \\
\text { Cas9 }\end{array}$ & YES & $\begin{array}{l}\text { Resistant } \\
\text { plants }\end{array}$ & 17 \\
\hline & $\begin{array}{l}\text { Powdery } \\
\text { mildew }\end{array}$ & $\begin{array}{l}\text { PMR4 / Host } \\
\text { S-gene }\end{array}$ & $\begin{array}{l}\text { Disease } \\
\text { facilitation }\end{array}$ & $\begin{array}{l}\text { CRISPR- } \\
\text { Cas9 }\end{array}$ & NO & $\begin{array}{l}\text { Resistant } \\
\text { plants }\end{array}$ & 18 \\
\hline & $\begin{array}{l}\text { Botrytis } \\
\text { cinerea }\end{array}$ & $\begin{array}{l}\text { SlMYC2 / Host } \\
\text { S-gene }\end{array}$ & $\begin{array}{l}\text { Disease } \\
\text { Inhibition }\end{array}$ & $\begin{array}{l}\text { CRISPR- } \\
\text { Cas9 }\end{array}$ & YES & $\begin{array}{l}\text { Susceptible } \\
\text { plants }\end{array}$ & 19 \\
\hline
\end{tabular}




\begin{tabular}{|c|c|c|c|c|c|c|c|}
\hline & TYLCV & $\begin{array}{l}\mathrm{CP}, \quad \text { Rep } \\
\text { Virus genome }\end{array}$ & Virus spread & $\begin{array}{l}\text { CRISPR- } \\
\text { Cas9 }\end{array}$ & NO & $\begin{array}{l}\text { Resistant } \\
\text { plants }\end{array}$ & 20 \\
\hline & $\begin{array}{l}\text { PVX, TMV, } \\
\text { TMV }\end{array}$ & $\begin{array}{l}\text { DCL2 / Virus } \\
\text { genome }\end{array}$ & Virus spread & $\begin{array}{l}\text { CRISPR- } \\
\text { Cas9 }\end{array}$ & NO & $\begin{array}{l}\text { Susceptible } \\
\text { plants }\end{array}$ & 21,22 \\
\hline & $\begin{array}{l}\text { Pepper } \\
\text { Mottle Virus }\end{array}$ & $\begin{array}{l}\text { eIF4E1 / Host } \\
\text { S-gene }\end{array}$ & $\begin{array}{l}\text { Viral } \\
\text { infection }\end{array}$ & $\begin{array}{l}\text { CRISPR- } \\
\text { Cas9 }\end{array}$ & YES & $\begin{array}{l}\text { Resistant } \\
\text { plants }\end{array}$ & 23 \\
\hline & $\begin{array}{l}\text { yellow leaf } \\
\text { curl virus }\end{array}$ & $\begin{array}{l}\mathrm{IR} \text { and } \mathrm{CP} / \\
\text { virus genome }\end{array}$ & $\begin{array}{l}\text { Viral } \\
\text { infection }\end{array}$ & $\begin{array}{l}\text { CRISPR- } \\
\text { Cas9 }\end{array}$ & YES & $\begin{array}{l}\text { Resistant } \\
\text { plants }\end{array}$ & 24 \\
\hline Cucumber & $\begin{array}{l}\text { RNA viral } \\
\text { disease }\end{array}$ & $\begin{array}{l}\text { elf4E / Host S- } \\
\text { gene }\end{array}$ & $\begin{array}{l}\text { Disease } \\
\text { facilitation }\end{array}$ & $\begin{array}{l}\text { CRISPR- } \\
\text { Cas9 }\end{array}$ & YES & $\begin{array}{l}\text { Resistant } \\
\text { plants }\end{array}$ & 25 \\
\hline Soybean & $\begin{array}{l}\text { Soybean } \\
\text { mosaic virus }\end{array}$ & $\begin{array}{l}G m F 3 H 1, \\
G m F 3 H 2 \text { and } \\
G m F N S I I-1\end{array}$ & $\begin{array}{l}\text { Isoflavonoid } \\
\text { synthesis }\end{array}$ & $\begin{array}{l}\text { CRISPR- } \\
\text { Cas9 }\end{array}$ & YES & $\begin{array}{l}\text { Resistant } \\
\text { plants }\end{array}$ & 26 \\
\hline
\end{tabular}


Table S2: Role of the CRISPR-Cas system in development of abiotic stress-resistant food crops

\begin{tabular}{|c|c|c|c|c|c|c|c|}
\hline $\begin{array}{l}\text { Food Crop } \\
\text { Species }\end{array}$ & $\begin{array}{l}\text { Abiotic } \\
\text { stress }\end{array}$ & $\begin{array}{l}\text { Targeted } \\
\text { gene/s }\end{array}$ & $\begin{array}{l}\text { Gene } \\
\text { function }\end{array}$ & System & $\begin{array}{l}\text { Transgene- } \\
\text { free Plants }\end{array}$ & Outcomes & Reference \\
\hline \multirow{8}{*}{ Rice } & \multirow{3}{*}{ Cold } & TIFYIa & $\begin{array}{l}\text { Cause } \\
\text { sensitivity }\end{array}$ & $\begin{array}{l}\text { CRISPR- } \\
\text { Cas9 }\end{array}$ & No & $\begin{array}{l}\text { Cold adaptive rice } \\
\text { plants }\end{array}$ & 27 \\
\hline & & $T I F Y 1 b$ & $\begin{array}{l}\text { Cause } \\
\text { sensitivity }\end{array}$ & $\begin{array}{l}\text { CRISPR- } \\
\text { Cas9 }\end{array}$ & No & $\begin{array}{l}\text { Cold adaptive rice } \\
\text { plants }\end{array}$ & 27 \\
\hline & & OsMYB30 & $\begin{array}{l}\text { Cause } \\
\text { sensitivity }\end{array}$ & $\begin{array}{l}\text { CRISPR- } \\
\text { Cas9 }\end{array}$ & No & $\begin{array}{l}\text { Improved cold } \\
\text { tolerance }\end{array}$ & 28 \\
\hline & \multirow{4}{*}{ Drought } & OsDST & $\begin{array}{l}\text { Cause } \\
\text { sensitivity }\end{array}$ & $\begin{array}{l}\text { CRISPR- } \\
\text { Cas9 }\end{array}$ & No & $\begin{array}{l}\text { Moderate level } \\
\text { tolerance }\end{array}$ & 29 \\
\hline & & OsEBP89 & $\begin{array}{l}\text { Cause } \\
\text { sensitivity }\end{array}$ & $\begin{array}{l}\text { CRISPR- } \\
\text { Cas9 }\end{array}$ & No & $\begin{array}{l}\text { Enhanced tolerance } \\
\text { to drought and } \\
\text { direct-seeding on } \\
\text { wet-land }\end{array}$ & 30 \\
\hline & & $O s S A P K 2$ & $\begin{array}{l}\text { Cause } \\
\text { sensitivity }\end{array}$ & $\begin{array}{l}\text { CRISPR- } \\
\text { Cas9 }\end{array}$ & No & $\begin{array}{l}\text { Enhanced drought } \\
\text { tolerance }\end{array}$ & 31 \\
\hline & & $\begin{array}{l}\text { OsSRL1, } \\
\text { OsSRL2 }\end{array}$ & $\begin{array}{l}\text { Cause } \\
\text { sensitivity }\end{array}$ & $\begin{array}{l}\text { CRISPR- } \\
\text { Cas9 }\end{array}$ & Yes & $\begin{array}{l}\text { Enhanced drought } \\
\text { tolerance }\end{array}$ & 32 \\
\hline & Salinity & OsRR22 & $\begin{array}{l}\text { Cause } \\
\text { sensitivity }\end{array}$ & $\begin{array}{l}\text { CRISPR- } \\
\text { Cas9 }\end{array}$ & Yes & $\begin{array}{l}\text { Enhanced salinity } \\
\text { tolerance }\end{array}$ & 33 \\
\hline
\end{tabular}




\begin{tabular}{|c|c|c|c|c|c|c|}
\hline & OsDST & $\begin{array}{l}\text { Control } \\
\text { tolerance }\end{array}$ & $\begin{array}{l}\text { CRISPR- } \\
\text { Cas9 }\end{array}$ & No & $\begin{array}{l}\text { Enhanced salinity } \\
\text { tolerance }\end{array}$ & 29 \\
\hline & qSORI & $\begin{array}{l}\text { Root } \\
\text { growth } \\
\text { angle }\end{array}$ & $\begin{array}{l}\text { CRISPR- } \\
\text { Cas9 }\end{array}$ & No & $\begin{array}{l}\text { Better root structure } \\
\text { for saline soils }\end{array}$ & 34 \\
\hline \multirow{3}{*}{$\begin{array}{l}\text { Heavy } \\
\text { metal }\end{array}$} & OsNramp5 & $\begin{array}{l}\text { Cause } \\
\text { sensitivity }\end{array}$ & $\begin{array}{l}\text { CRISPR- } \\
\text { Cas9 }\end{array}$ & No & $\begin{array}{l}\text { Decreased } \quad \mathrm{Cd} \\
\text { accumulation }\end{array}$ & 35 \\
\hline & $\begin{array}{l}\text { OsLCT1, } \\
\text { OsNramp5 }\end{array}$ & $\begin{array}{l}\text { Cause } \\
\text { sensitivity }\end{array}$ & $\begin{array}{l}\text { CRISPR- } \\
\text { Cas9 }\end{array}$ & Yes & $\begin{array}{l}\text { Decreased } \quad \mathrm{Cd} \\
\text { accumulation }\end{array}$ & 36 \\
\hline & OsNramp5 & $\begin{array}{l}\text { Cause } \\
\text { sensitivity }\end{array}$ & $\begin{array}{l}\text { CRISPR- } \\
\text { Cas9 }\end{array}$ & Yes & $\begin{array}{l}\text { Decreased } \quad \mathrm{Cd} \\
\text { accumulation }\end{array}$ & 37 \\
\hline \multirow{4}{*}{ Herbicide } & OsALS & $\begin{array}{l}\text { Cause } \\
\text { sensitivity }\end{array}$ & $\begin{array}{l}\text { CRISPR- } \\
\text { Cas9 based } \\
\text { cytosine } \\
\text { base editing }\end{array}$ & Yes & Herbicide tolerance & 38 \\
\hline & $\begin{array}{l}\text { OsALS } \\
\text { (novel allele } \\
G 628 W \text { ) }\end{array}$ & $\begin{array}{l}\text { Cause } \\
\text { sensitivity }\end{array}$ & $\begin{array}{l}\text { CRISPR- } \\
\text { Cas9 }\end{array}$ & Yes & Herbicide tolerance & 39 \\
\hline & OsALS & $\begin{array}{l}\text { Cause } \\
\text { sensitivity }\end{array}$ & $\begin{array}{l}\text { CRISPR- } \\
\text { nCas9-RT }\end{array}$ & Yes & Herbicide tolerance & 40 \\
\hline & OsALS1 & Cause & Base- & No & Herbicide tolerance & 41 \\
\hline
\end{tabular}




\begin{tabular}{|c|c|c|c|c|c|c|c|}
\hline & & & sensitivity & $\begin{array}{l}\text { editing- } \\
\text { mediated } \\
\text { gene } \\
\text { evolution }\end{array}$ & & & \\
\hline & & OsALS & $\begin{array}{l}\text { Cause } \\
\text { sensitivity }\end{array}$ & $\begin{array}{l}\text { CRISPR- } \\
\text { Cpf1 }\end{array}$ & Yes & Herbicide tolerance & 42 \\
\hline & & OsALS & $\begin{array}{l}\text { Cause } \\
\text { sensitivity }\end{array}$ & $\begin{array}{l}\text { CRISPR- } \\
\text { Cas9 }\end{array}$ & No & Herbicide tolerance & 43 \\
\hline \multirow{4}{*}{ Maize } & Drought & ARGOS 8 & $\begin{array}{l}\text { Cause } \\
\text { sensitivity }\end{array}$ & $\begin{array}{l}\text { CRISPR- } \\
\text { Cas9 }\end{array}$ & No & $\begin{array}{l}\text { Enhanced drought } \\
\text { tolerance }\end{array}$ & 44 \\
\hline & \multirow{3}{*}{ Herbicide } & $\begin{array}{l}Z m A L S 1, \\
Z m A L S 2\end{array}$ & $\begin{array}{l}\text { Cause } \\
\text { sensitivity }\end{array}$ & $\begin{array}{l}\text { CRISPR- } \\
\text { nCas9-RT }\end{array}$ & Yes & $\begin{array}{l}\text { Herbicide } \\
\text { resistance }\end{array}$ & 45 \\
\hline & & $\begin{array}{l}Z m A L S 1, \\
Z m A L S 2\end{array}$ & $\begin{array}{l}\text { Cause } \\
\text { sensitivity }\end{array}$ & $\begin{array}{l}\text { CRISPR- } \\
\text { Cas- } \\
\text { mediated } \\
\text { base editing }\end{array}$ & Yes & $\begin{array}{l}\text { Sulfonylurea } \\
\text { herbicide-resistant } \\
\text { plant }\end{array}$ & 46 \\
\hline & & $Z m A L S 2$ & $\begin{array}{l}\text { Cause } \\
\text { sensitivity }\end{array}$ & $\begin{array}{l}\text { CRISPR- } \\
\text { Cas9 }\end{array}$ & No & Herbicide resistant & 47 \\
\hline Tomato & Heat & SIMAPK3 & $\begin{array}{l}\text { Cause } \\
\text { sensitivity }\end{array}$ & $\begin{array}{l}\text { CRISPR- } \\
\text { Cas9 }\end{array}$ & No & $\begin{array}{l}\text { Enhanced heat } \\
\text { tolerance }\end{array}$ & 48 \\
\hline
\end{tabular}




\begin{tabular}{|c|c|c|c|c|c|c|c|}
\hline & & SIAGL6 & $\begin{array}{l}\text { Cause } \\
\text { sensitivity }\end{array}$ & $\begin{array}{l}\text { CRISPR- } \\
\text { Cas9 }\end{array}$ & No & $\begin{array}{l}\text { Enhanced heat } \\
\text { tolerance }\end{array}$ & 49 \\
\hline & Salinity & SIARF4 & $\begin{array}{l}\text { Cause } \\
\text { sensitivity }\end{array}$ & $\begin{array}{l}\text { CRISPR- } \\
\text { Cas9 }\end{array}$ & No & $\begin{array}{l}\text { Enhanced salinity } \\
\text { tolerance }\end{array}$ & 50 \\
\hline & Herbicide & SIALS & $\begin{array}{l}\text { Cause } \\
\text { sensitivity }\end{array}$ & $\begin{array}{l}\text { CRISPR- } \\
\text { Cas9 }\end{array}$ & Yes & Herbicide tolerance & 51 \\
\hline $\begin{array}{l}\text { Oilseed } \\
\text { rape }\end{array}$ & Herbicide & $B n A L S 1$ & $\begin{array}{l}\text { Cause } \\
\text { sensitivity }\end{array}$ & $\begin{array}{l}\text { CRISPR- } \\
\text { Cas- } \\
\text { mediated } \\
\text { base editing }\end{array}$ & Yes & Herbicide tolerance & 52 \\
\hline Chickpea & Drought & $\begin{array}{l}\text { Coumarate } \\
\text { ligase } \\
(4 C L) \quad \text { and } \\
\text { Reveille } 7 \\
(\text { RVE7) }\end{array}$ & $\begin{array}{l}\text { Cause } \\
\text { sensitivity }\end{array}$ & $\begin{array}{l}\text { CRISPR- } \\
\text { Cas9 }\end{array}$ & Yes & $\begin{array}{l}\text { Enhanced drought } \\
\text { tolerance }\end{array}$ & 53 \\
\hline
\end{tabular}


Table S3. Summary of the role of the CRISPR-Cas system in grain yield, quality, and plant architecture improvement

\begin{tabular}{|c|c|c|c|c|c|c|c|c|}
\hline Application & $\begin{array}{l}\text { Food } \\
\text { Crop } \\
\text { Species }\end{array}$ & Trait & $\begin{array}{l}\text { Targeted } \\
\text { gene/s }\end{array}$ & $\begin{array}{l}\text { Gene } \\
\text { function }\end{array}$ & System & $\begin{array}{l}\text { Transgene- } \\
\text { free Plants }\end{array}$ & Outcomes & Reference \\
\hline \multirow{5}{*}{$\begin{array}{l}\text { Yield } \\
\text { Improvement }\end{array}$} & \multirow{5}{*}{ Rice } & Grain size & OsGS3 & $\begin{array}{l}\text { Negatively } \\
\text { regulates the } \\
\text { grain size }\end{array}$ & $\begin{array}{l}\text { CRISPR- } \\
\text { Cas9 }\end{array}$ & Yes & $\begin{array}{l}\text { Increase } \\
\text { grain size }\end{array}$ & 54 \\
\hline & & $\begin{array}{l}\text { Grain width } \\
\text { and weight }\end{array}$ & $\begin{array}{l}\text { OsGW2, } \\
\text { OsGW5, TGW6 }\end{array}$ & $\begin{array}{l}\text { Negatively } \\
\text { regulates the } \\
\text { grain width } \\
\text { and weight }\end{array}$ & $\begin{array}{l}\text { CRISPR- } \\
\text { Cas9 }\end{array}$ & Yes & $\begin{array}{l}\text { Increase } \\
\text { grain width } \\
\text { and weight }\end{array}$ & $55-57$ \\
\hline & & Grain number & OsGnla & $\begin{array}{l}\text { Negatively } \\
\text { regulates the } \\
\text { grain number }\end{array}$ & $\begin{array}{l}\text { CRISPR- } \\
\text { Cas9 }\end{array}$ & Yes & $\begin{array}{l}\text { Increase } \\
\text { grain } \\
\text { number }\end{array}$ & $55,58-60$ \\
\hline & & Grain yield & OsDEP1 & $\begin{array}{l}\text { inflorescence } \\
\text { architecture } \\
\text { and plant } \\
\text { height }\end{array}$ & $\begin{array}{l}\text { CRISPR- } \\
\text { Cas9 }\end{array}$ & Yes & $\begin{array}{l}\text { Increase } \\
\text { yield }\end{array}$ & 60 \\
\hline & & $\begin{array}{l}\text { Plant growth } \\
\text { and grain yield }\end{array}$ & $\begin{array}{l}P Y L 1-P Y L 6 \\
\text { and } P Y L 12(g p- \\
1) \text {, }\end{array}$ & $\begin{array}{l}\text { better grain } \\
\text { productivity } \\
\text { and growth }\end{array}$ & $\begin{array}{l}\text { CRISPR- } \\
\text { Cas9 }\end{array}$ & No & $\begin{array}{l}\text { Improved } \\
\text { grain } \\
\text { productivity }\end{array}$ & 59 \\
\hline
\end{tabular}




\begin{tabular}{|c|c|c|c|c|c|c|c|}
\hline & & $\begin{array}{l}P Y L 7-P Y L 11 \\
\text { and } P Y L 13(g p- \\
\text { 2) }\end{array}$ & & & & $\begin{array}{l}\text { and plant } \\
\text { growth }\end{array}$ & \\
\hline & Grain yield & OsPIN5b & $\begin{array}{l}\text { Negatively } \\
\text { regulates } \\
\text { yield } \\
\text { parameters }\end{array}$ & $\begin{array}{l}\text { CRISPR- } \\
\text { Cas9 }\end{array}$ & Yes & $\begin{array}{l}\text { Increase } \\
\text { grain yield }\end{array}$ & 28 \\
\hline & Grain yield & OsLOGL5 & $\begin{array}{l}\text { Negatively } \\
\text { regulates root } \\
\text { growth, tiller } \\
\text { number, and } \\
\text { yield }\end{array}$ & $\begin{array}{l}\text { CRISPR- } \\
\text { Cas9 }\end{array}$ & No & $\begin{array}{l}\text { Increase } \\
\text { grain yield }\end{array}$ & 61 \\
\hline & Tiller number & $O s A A P 3$ & $\begin{array}{l}\text { Negatively } \\
\text { regulates } \\
\text { number of } \\
\text { plant tillers }\end{array}$ & $\begin{array}{l}\text { CRISPR- } \\
\text { Cas9 }\end{array}$ & No & $\begin{array}{l}\text { Increase } \\
\text { grain yield } \\
\text { by } \\
\text { increasing } \\
\text { tiller } \\
\text { numbers }\end{array}$ & 62 \\
\hline Wheat & Grain size & TaGS5-3A & $\begin{array}{l}\text { Negatively } \\
\text { regulates the } \\
\text { grain size }\end{array}$ & $\begin{array}{l}\text { CRISPR- } \\
\text { Cas9 }\end{array}$ & Yes & $\begin{array}{l}\text { Larger } \\
\text { kernel size } \\
\text { and yield }\end{array}$ & 63 \\
\hline
\end{tabular}




\begin{tabular}{|c|c|c|c|c|c|c|c|}
\hline & Grain number & TaCKX2-D1 & $\begin{array}{l}\text { Negatively } \\
\text { regulates } \\
\text { grain number } \\
\text { per spikelet }\end{array}$ & $\begin{array}{l}\text { CRISPR- } \\
\text { Cas9 }\end{array}$ & No & $\begin{array}{l}\text { Boost grain } \\
\text { number per } \\
\text { spikelet }\end{array}$ & 64 \\
\hline & Grain yield & $\begin{array}{l}\text { TaDEP1, } \\
\text { TaGASR7, } \\
\text { TaLOX2, } \\
\text { TaNAC2, } \\
\text { TaPIN1, } \\
T a G W 2, \\
T a G L W 7, \\
T a G W 2, \\
T a G W 8\end{array}$ & $\begin{array}{l}\text { Inflorescence } \\
\text { architecture } \\
\text { and plant } \\
\text { height } \\
\text { regulator, } \\
\text { lipoxygenase, } \\
\text { negative } \\
\text { regulator of } \\
\text { grain weight }\end{array}$ & $\begin{array}{l}\text { CRISPR- } \\
\text { Cas9 }\end{array}$ & Yes & $\begin{array}{l}\text { Boost grain } \\
\text { yield }\end{array}$ & 64-66 \\
\hline Barley & $\begin{array}{l}\text { Development } \\
\text { and yield }\end{array}$ & $H v C K X 1$ & $\begin{array}{l}\text { cytokinin } \\
\text { metabolism }\end{array}$ & $\begin{array}{l}\text { CRISPR- } \\
\text { Cas9 }\end{array}$ & No & $\begin{array}{l}\text { Increase } \\
\text { grain yield }\end{array}$ & 67 \\
\hline \multirow[b]{2}{*}{ Tomato } & Fruit size & $\begin{array}{l}\text { SlCLV3 } \\
\text { Promoter }\end{array}$ & $\begin{array}{l}\text { signaling } \\
\text { peptide gene }\end{array}$ & $\begin{array}{l}\text { CRISPR- } \\
\text { Cas9 }\end{array}$ & Yes & $\begin{array}{l}\text { Enhanced } \\
\text { fruit size }\end{array}$ & 68 \\
\hline & Fruit size & SIENO & $\begin{array}{l}\text { an AP2/ERF } \\
\text { transcription } \\
\text { factor which } \\
\text { regulates }\end{array}$ & $\begin{array}{l}\text { CRISPR- } \\
\text { Cas9 }\end{array}$ & No & $\begin{array}{l}\text { Enhanced } \\
\text { fruit size }\end{array}$ & 69 \\
\hline
\end{tabular}




\begin{tabular}{|c|c|c|c|c|c|c|c|c|}
\hline & & & & $\begin{array}{l}\text { floral } \\
\text { meristem } \\
\text { activity }\end{array}$ & & & & \\
\hline \multirow{4}{*}{$\begin{array}{l}\text { Quality } \\
\text { Improvement }\end{array}$} & \multirow{4}{*}{ Rice } & \multirow{4}{*}{$\begin{array}{l}\text { Cooking and } \\
\text { eating quality }\end{array}$} & $\begin{array}{l}\text { OsAAP6, } \\
\text { OsAAP10 }\end{array}$ & $\begin{array}{l}\text { Amino acid } \\
\text { transporter } \\
\text { controlling } \\
\text { grain protein } \\
\text { content } \\
\text { (GPC) }\end{array}$ & $\begin{array}{l}\text { CRISPR- } \\
\text { Cas9 }\end{array}$ & No & $\begin{array}{l}\text { Increasing } \\
\text { eating and } \\
\text { cooking } \\
\text { quality } \\
\text { (ECQ), } \\
\text { reducing } \\
\text { GPC }\end{array}$ & 70 \\
\hline & & & OsAAP10 & $\begin{array}{l}\text { AGPase } \\
\text { (starch } \\
\text { biosynthesis) }\end{array}$ & $\begin{array}{l}\text { CRISPR- } \\
\text { Cas9 }\end{array}$ & No & $\begin{array}{l}\text { Starch } \\
\text { depletion in } \\
\text { leaves }\end{array}$ & 71 \\
\hline & & & OsWaxy & $\begin{array}{l}\text { GBSS } \\
\text { (amylose } \\
\text { synthesis) }\end{array}$ & $\begin{array}{l}\text { CRISPR- } \\
\text { Cas9 }\end{array}$ & Yes & $\begin{array}{l}\text { Decrease in } \\
\text { amylose } \\
\text { content } \\
\text { (glutinous } \\
\text { rice } \\
\text { production) }\end{array}$ & 72 \\
\hline & & & $O s B E I$ and & Starch & CRISPR- & Yes & High amylose & 73 \\
\hline
\end{tabular}




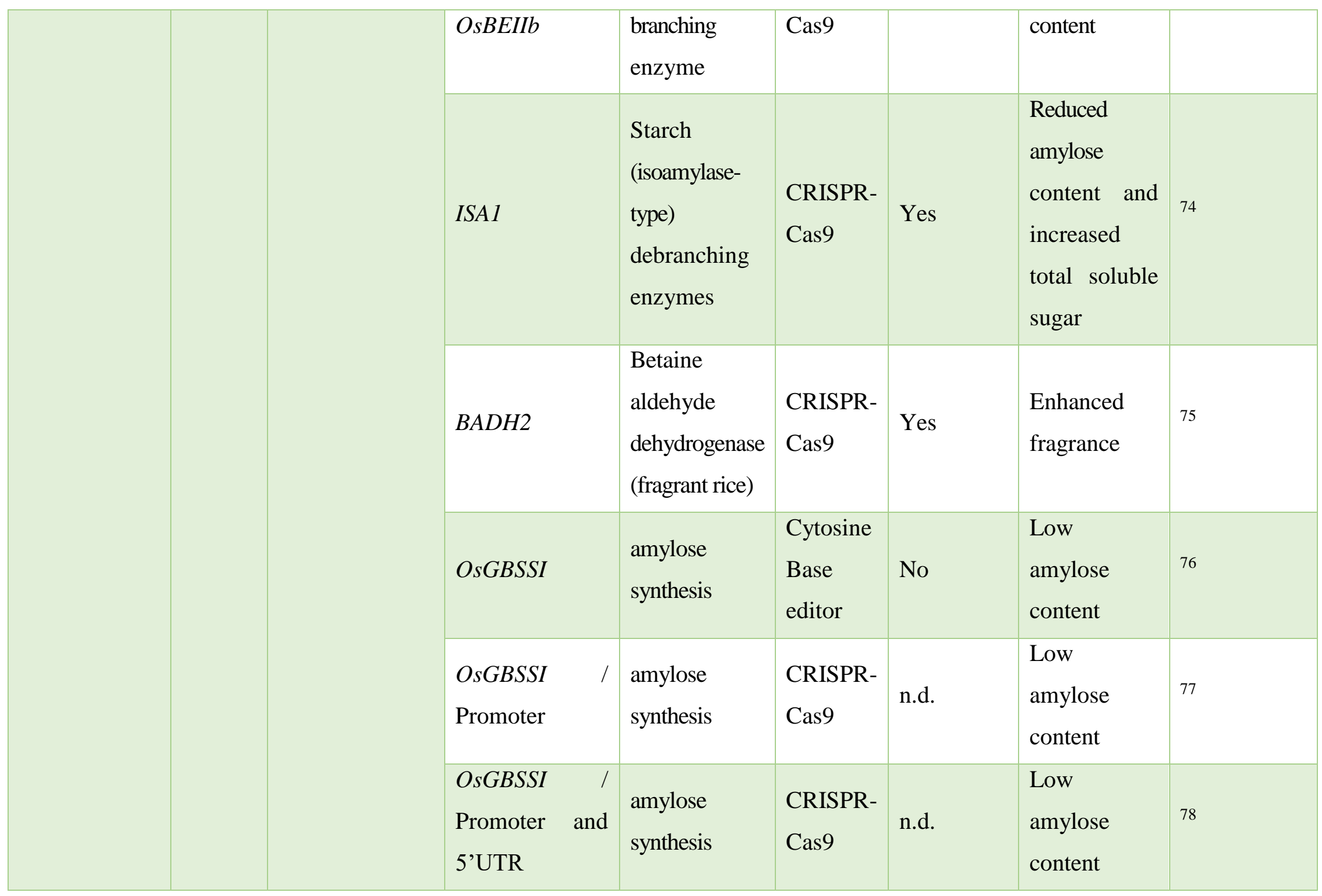




\begin{tabular}{|c|c|c|c|c|c|c|c|}
\hline & & $O s P L D \alpha 1$ & $\begin{array}{l}\text { amylose } \\
\text { synthesis }\end{array}$ & $\begin{array}{l}\text { CRISPR- } \\
\text { Cas9 }\end{array}$ & n.d. & $\begin{array}{l}\text { Reduced } \\
\text { amylose } \\
\text { content }\end{array}$ & 79 \\
\hline & \multirow{3}{*}{$\begin{array}{l}\text { Nutrition } \\
\text { quality }\end{array}$} & $\begin{array}{l}\text { Insertion of } \\
5.2 \mathrm{~kb} \\
\text { carotenoid } \\
\text { cassette }\end{array}$ & $\begin{array}{l}\beta \text {-carotene } \\
\text { content }\end{array}$ & $\begin{array}{l}\text { CRISPR- } \\
\text { Cas9 }\end{array}$ & Yes & $\begin{array}{l}\text { Increased } \beta \text { - } \\
\text { carotene } \\
\text { content }\end{array}$ & 80 \\
\hline & & OsFAD2-1 & $\begin{array}{l}\text { Oleic acid } \\
\text { contents }\end{array}$ & $\begin{array}{l}\text { CRISPR- } \\
\text { Cas9 }\end{array}$ & n.d. & $\begin{array}{l}\text { Increased } \\
\text { oleic acid } \\
\text { proportion }\end{array}$ & 81 \\
\hline & & $O s P L D \alpha 1$ & $\begin{array}{l}\text { Phytic acid } \\
\text { synthesis }\end{array}$ & $\begin{array}{l}\text { CRISPR- } \\
\text { Cas9 }\end{array}$ & n.d. & $\begin{array}{l}\text { lower } \\
\text { accumulation } \\
\text { of phytic } \\
\text { acid }\end{array}$ & 82 \\
\hline Maize & $\begin{array}{l}\text { Cooking/baking } \\
\text { quality }\end{array}$ & $\begin{array}{l}Z m G B S S I \quad(W x \\
\text { gene })\end{array}$ & $\begin{array}{l}\text { amylose } \\
\text { synthesis }\end{array}$ & $\begin{array}{l}\text { CRISPR- } \\
\text { Cas9 }\end{array}$ & Yes & $\begin{array}{l}\text { waxy corn } \\
\text { hybrids }\end{array}$ & 83 \\
\hline Potato & $\begin{array}{l}\text { Cooking and } \\
\text { eating quality }\end{array}$ & $\begin{array}{l}\text { StGBSSI, } \\
\text { StSBE1, } \\
\text { StSBE2 }\end{array}$ & $\begin{array}{l}\text { amylose } \\
\text { synthesis }\end{array}$ & $\begin{array}{l}\text { CRISPR- } \\
\text { Cas9 and } \\
\text { Base } \\
\text { Editing }\end{array}$ & Yes & Waxy potato & 84 \\
\hline Sweet & Starch quality & $I b G B S S I$ & Reduce starch & CRISPR- & No & Improved & 85 \\
\hline
\end{tabular}




\begin{tabular}{|l|l|l|l|l|l|l|l|l|}
\hline & potato & & quality & Cas9 & & starch \\
quality
\end{tabular}

n.d. $=$ Not defined . 
Table S4. Applications of the CRISPR-Cas system in plant breeding

\begin{tabular}{|c|c|c|c|c|c|}
\hline Application & Crop & $\begin{array}{l}\text { Genome } \\
\text { Editing } \\
\text { Effector }\end{array}$ & $\begin{array}{l}\text { Mutant } \\
\text { Type }\end{array}$ & Target Gene/Region & Reference \\
\hline \multirow{2}{*}{$\begin{array}{l}\text { Breakage of Self } \\
\text { incompatibility } \\
\text { distant lines }\end{array}$} & $\begin{array}{l}\text { Rice } O \text {. sativa and } \\
\text { O. japonica cross }\end{array}$ & Cas9 & Indel & Sc Locus knockout & 89 \\
\hline & $\begin{array}{l}\text { Rice } O . \text { sativa \& } O . \\
\text { japonica crossed } \\
\text { with } O . \text { glaberrima }\end{array}$ & Cas9 & Indel & OgTPR1 at the S1 Locus & 90 \\
\hline \multirow{6}{*}{$\begin{array}{l}\text { Chromosomal } \\
\text { Rearrangements }\end{array}$} & Arabidopsis thaliana & Cas9 & $\begin{array}{l}\text { Large } \\
\text { Indel }\end{array}$ & Chr. 1, 3, and 4 & 91 \\
\hline & Nicotiana tabacum & Cas9 & $\begin{array}{l}\text { Large } \\
\text { Indel }\end{array}$ & Multiple Chr. & 92 \\
\hline & Arabidopsis thaliana & Cas9 & $\begin{array}{l}\text { Large } \\
\text { Indel }\end{array}$ & Multiple Chr. & 93 \\
\hline & Arabidopsis thaliana & Cas9 & $\begin{array}{l}\text { Large } \\
\text { Indel }\end{array}$ & Multiple Chr. & 94 \\
\hline & Zea mays & Cas9 & $\begin{array}{l}75.5 \mathrm{Mb} \\
\text { Inversion }\end{array}$ & Chromosome 2 & 95 \\
\hline & Arabidopsis thaliana & Cas9 & $\begin{array}{l}\text { Transloc } \\
\text { ation }\end{array}$ & $\begin{array}{l}\text { Between Chr. } 1 \& 2 \text { and } 1 \\
\& 5\end{array}$ & 96 \\
\hline
\end{tabular}




\begin{tabular}{|c|c|c|c|c|c|}
\hline & Nicotiana tabacum & Cas9 & $\begin{array}{l}\text { Transloc } \\
\text { ation }\end{array}$ & Chr1, 7, 9, 12 & 97 \\
\hline & Arabidopsis thaliana & Cas9 & Inversion & Chr. 4 & 98 \\
\hline & Rice & Cas9 & Indel & Chr. 4 & 99 \\
\hline \multirow{9}{*}{ Haploid induction } & Maize & Cas9 & Indel & $M T L$ gene & 100 \\
\hline & Maize & Cas9 & Indel & CENH3 & 101 \\
\hline & Maize & Cas9 & Indel & ZmPLA1 & 102 \\
\hline & Arabidopsis thaliana & Cas9 & Indel & CENH3 & 101 \\
\hline & Maize & Cas9 & Indel & $Z m D M P$ & 103 \\
\hline & Wheat & Cas9 & Indel & TaMTL & 101 \\
\hline & Wheat & Cas9 & Indel & TaPLA-A and TaPLA-D & 104 \\
\hline & Rice & Cas 9 & Indel & OsMATL & 105 \\
\hline & Tobacco & Cas9 & Indel & $P s A S G R-B B M L$ & 106 \\
\hline \multirow{8}{*}{$\begin{array}{l}\text { Generation of Male } \\
\text { sterility }\end{array}$} & Wheat & Cas9 & Indel & TaMS1 & 107 \\
\hline & Wheat & Cas9 & Indel & TaNP1 & 108 \\
\hline & Wheat & Cas9 & Indel & TaCalS5 \& TaRPG1 & 109 \\
\hline & Tomato & Cas9 & Indel & SlMS10 & 110 \\
\hline & Maize & Cas9 & Indel & ZmTMS5 & 111 \\
\hline & Maize & Cas9 & Indel & ZmDCL5 & 112 \\
\hline & Rice & Cas9 & Indel & OsACOS12 & 113 \\
\hline & Rice & Cas9 & Indel & PTGMS2-1 & 114 \\
\hline
\end{tabular}




\begin{tabular}{|c|c|c|c|c|c|}
\hline & Rice & Cas9 & $\begin{array}{l}\mathrm{C} \text { to } \mathrm{T} \\
\text { substituti } \\
\text { on }\end{array}$ & Oswbcl1 & 115 \\
\hline & Rice & Cas9 & Indel & OsTMS5 & 116 \\
\hline & Rice & Cas9 & Indel & OsRMS & 117 \\
\hline & Rice & Cas9 & Indel & $O s D G D 2 \beta$ & 118 \\
\hline & Rice & Cas9 & Indel & OsCYP703A3 & 119 \\
\hline \multirow{11}{*}{ Fixation of hybrid } & Rice & Cas9 & Indel & OsPAIRI & 120 \\
\hline & Rice & Cas9 & Indel & OsREC8 & 120 \\
\hline & Rice & Cas9 & Indel & OsOSD1 & 120 \\
\hline & Rice & Cas9 & Indel & OsMTL & 120 \\
\hline & Hieracium & Cas9 & Indel & $P D S$ & 121 \\
\hline & Poa pratensis & Cas9 & Indel & APOSTART_6 & 122 \\
\hline & Arabidopsis thaliana & Cas9 & Indel & $\begin{array}{l}\text { AtSPO11-1 + AtREC8 }+ \\
\text { AtOSD1 }\end{array}$ & 123 \\
\hline & Arabidopsis thaliana & Cas9 & Indel & $\begin{array}{l}\text { AtSPO11-1 + AtREC8 + } \\
\text { AtOSD1 + GEM }\end{array}$ & 123 \\
\hline & Rice & Cas9 & Indel & dyad + GEM & 123 \\
\hline & Rice & Cas9 & Indel & $\begin{array}{l}\text { AtSPO11-1 + AtREC8 + } \\
\text { AtOSD1 + BBM1 }\end{array}$ & 123 \\
\hline & Rice & Cas9 & Indel & OsPAIR1 + OsREC8 + & 123 \\
\hline
\end{tabular}




\begin{tabular}{|c|c|c|c|c|c|}
\hline & & & & OsOSD1 + OsMATL & \\
\hline & Rice & Cas9 & Indel & $\begin{array}{l}\text { OsSPO11-1 + OsREC8 }+ \\
\text { OsOSD1 + OsMATL }\end{array}$ & 123 \\
\hline & Potato & Cas9 & Indel & S-RNase & 124 \\
\hline & Cabbage & Cas9 & Indel & S-receptor kinase & 125 \\
\hline & Oilseed Rape & Cas9 & Indel & M-locus protein kinase & 126 \\
\hline & Rye Grass & Cas9 & Indel & LpDMC1 and LpCENH3 & 127 \\
\hline & Tomato & Cas9 & Indel & FPS2 & 128 \\
\hline Manipulation of Self- & Brassica oleracea & Cas9 & Indel & BoSRK3 & 129 \\
\hline Incompatibility & Brassica oleracea & Cas9 & Indel & BoMS1 & 129 \\
\hline & Cabbage & Cas9 & Indel & BoPDS & 130 \\
\hline & Brassica napus & Cas9 & Indel & $\begin{array}{l}\text { BnaA3.MLPK, } \\
\text { BnaC3.MLPK, } \\
\text { BnaA4.MLPK } \\
\text { BnaC4.MLPK }\end{array}$ & 126 \\
\hline & S. pimpinellifolium & Cas9 & Indel & $\begin{array}{l}\text { SP, SP5G, SICLV3, } \\
\text { SIWUS }\end{array}$ & 131,132 \\
\hline domestication & Physalis pruinosa & Cas9 & Indel & $\begin{array}{l}\text { JOINTLESS-2, SP, SP5G, } \\
\text { SICLV3, SIWUS }\end{array}$ & 133 \\
\hline & African Rice & Cas9 & Indel & $\begin{array}{l}\text { GS3, GW2, HTD1 and } \\
\text { GN1A }\end{array}$ & 134 \\
\hline
\end{tabular}




\begin{tabular}{|c|c|c|c|c|c|}
\hline & Coffea canephora & Cas9 & Indel & CcPDS & 135 \\
\hline \multirow{7}{*}{ Gene Pyramiding } & Tomato & Cas9 & Indel & SIIAA9 & 136 \\
\hline & Tomato & Cas9 & Indel & ANT1 & 137 \\
\hline & Rice & Cas9 & Indel & GR1 and GR2 & 80 \\
\hline & Rice & Cas9 & Indel & EPSPS & 138 \\
\hline & Rice & Cas9 & Indel & ALS2 & 43 \\
\hline & Rice & Cpf1 & Indel & COA1 & 139 \\
\hline & Maize & Cas9 & Indel & LIG1 & 47 \\
\hline
\end{tabular}


Table S5. CRISPR-based multiplex genome editing in crops

\begin{tabular}{|c|c|c|c|c|c|}
\hline \multirow{3}{*}{ Crop } & \multicolumn{5}{|l|}{ Genome } \\
\hline & Editing & Trait of interest & Mutant Type & Target Gene/Region & Reference \\
\hline & \multicolumn{5}{|l|}{ Effector } \\
\hline $\begin{array}{l}\text { Arabidopsis } \\
\text { thaliana }\end{array}$ & Cas9 & - & Indel & $A t P D S 3$ and $A t F L S 2$ & 140 \\
\hline Zea mays & Cas9 & - & Indel & Two target size of ZmHKTl & 141 \\
\hline Rice & Cas9 & Anthocyanin pathway & Indel & OsGSTU, OsMRP15, and OsAnP & 72 \\
\hline Rice & Cas9 & $\begin{array}{l}\text { Cellular Signalling } \\
\text { Pathways }\end{array}$ & Indel & $\begin{array}{l}\text { OsMPK1, OsMPK2, OsMPK5, } \\
\text { OsMPK6 }\end{array}$ & 142 \\
\hline Maize & Cas9 & $\begin{array}{l}\text { Endosperm-specific core } \\
\text { transcription factor }\end{array}$ & Indel & $Z m M A D S, Z m M Y B R, Z m A P 2$ & 143 \\
\hline Wheat & Cas9 & Multiple traits & Indel & $\begin{array}{l}\text { TaGW2, TaLpx-1, TaMLO and } Q \\
\text { gene }\end{array}$ & 144 \\
\hline $\begin{array}{l}\text { Arabidopsis } \\
\text { thaliana }\end{array}$ & Cas9 & $\mathrm{ABA}$ receptor genes & Indel & $\begin{array}{l}\text { AtPyrl, Atpyl1, Atpyl2, Atpyl4, } \\
\text { Atpyl5 and Atpyl8 }\end{array}$ & 145 \\
\hline Rice & FnCpf1 & Receptor like Kinases & Indel & $\begin{array}{l}\text { OsRLK-798, OsRLK-798, OsRLK- } \\
802 \text { and } O s R L K-803\end{array}$ & 146 \\
\hline Rice & LbCpf1 & CYP81A family & Indel & $\begin{array}{l}O s B E L-230, O s B E L-240, O s B E L- \\
250 \text { and } O s B E L-260\end{array}$ & 146 \\
\hline Rice & Cas9 & Agronomic traits & Indel & BADH2, DEP1, Gnla, QTL, GS3, & 147 \\
\hline
\end{tabular}




\begin{tabular}{|c|c|c|c|c|c|}
\hline & & & & $G W 2, H d 1, E P 3$ and LPA1 & \\
\hline Cotton & Cas9 & - & Indel & GhPDS and GhEF1 & 148 \\
\hline $\begin{array}{l}\text { Arabidopsis } \\
\text { thaliana }\end{array}$ & Cas9 & MPK genes & Indel & $\begin{array}{l}\text { AtMPK2, AtMPK3, AtMPK4 and } \\
\text { AtMPK6 }\end{array}$ & 149 \\
\hline $\begin{array}{l}\text { Nicotiana } \\
\text { benthamiana }\end{array}$ & Cas9 & NbAGO1 paralogs & Indel & NbAGO1 paralogs & 150 \\
\hline Rice & $\begin{array}{l}\text { Cpf1 and } \\
\text { Cas9 }\end{array}$ & LEA gene family & Indel & OsLEA1 and OsLEA2 & 151 \\
\hline \multirow[t]{2}{*}{ Rice } & Cas9 & Herbicide Tolerance & Indel & $A L S$ and $m E G F P$ & 152 \\
\hline & $\begin{array}{l}\text { Cas9- and } \\
\text { Cpf1 }\end{array}$ & MPK gene family & Indel & $P D S, M P K 1, M P K 2, M P K 5$ & 153 \\
\hline Wheat & Cas9 & Agronomic traits & Indel & TaGW2, TaLpx-1, and TaMLO & 154 \\
\hline Wheat & Cas9 & $\begin{array}{l}\text { Growth and development } \\
\text { related multiple traits }\end{array}$ & Indel & TaDA1, TaPDS and TaNCED1 & 155 \\
\hline Brassica & Cas9 & $\begin{array}{l}\text { Resistance to Sclerotinia } \\
\text { sclerotiorum }\end{array}$ & Indel & $B n W R K Y 11$ and BnWRKY70 & 156 \\
\hline Tomato & Cas9 & Lycopene synthesis & Indel & $\begin{array}{l}\text { SlGGPPS, SlZISO, SlDXS, SlG3P } \\
\text { and SlPDS, }\end{array}$ & 157 \\
\hline Tomato & Cas9 & - & Indel & Three target sites of SINADK2A & 158 \\
\hline
\end{tabular}




\begin{tabular}{|c|c|c|c|c|c|}
\hline Tomato & Cas9 & $\gamma$-aminobutyric acid & Indel & $\begin{array}{l}\text { GABA-TP1, GABA-TP2, } \\
\text { GABA-TP3, CAT9 and SSADH }\end{array}$ & 159 \\
\hline $\begin{array}{l}\text { Arabidopsis } \\
\text { thaliana }\end{array}$ & Cas9 & $\begin{array}{l}\text { Ribosomal Protein Large } \\
10 \text { subunits }\end{array}$ & Indel & $\begin{array}{l}\text { AtRPL10A, AtRPL10B and } \\
\text { AtRPL10C }\end{array}$ & 160 \\
\hline Rice & FnCpf1 & - & Indel & OsDEP1, OsEPFL9 & 161 \\
\hline Rice & LbCpf1- & - & Indel & OSROC5, OSEPFL9 & 161 \\
\hline Potato & Cas9 & $\begin{array}{l}\text { Alpha-solanine-free hairy } \\
\text { roots }\end{array}$ & Indel & Multiple target sites of St16DOX & 162 \\
\hline Kiwi Fruit & Cas9 & Phytoene desaturase & Indel & Multiple target sites of AcPDS & 163 \\
\hline $\begin{array}{l}\text { Catharanthus } \\
\text { roseus }\end{array}$ & Cas9 & Heavy Metals & Indel & MEDOS1 to 4 & 164 \\
\hline Barely & Cas9 & $\begin{array}{l}\text { Cytokinin } \\
\text { oxidase/dehydrogenase }\end{array}$ & Indel & $H v C K X 1, H v C K X 3$ & 165 \\
\hline $\begin{array}{l}\text { Arabidopsis } \\
\text { thaliana }\end{array}$ & Cas9 & - & Indel & $A t Y A O, A t C D C 45$ & 166 \\
\hline $\begin{array}{l}\text { Physcomitrella } \\
\text { patens }\end{array}$ & Cpf1 & - & Indel & $\begin{array}{l}\text { HDS19, HDS21, HDS22, HSFA1, } \\
\text { HSFA2, HSFB4 }\end{array}$ & 167 \\
\hline
\end{tabular}




\begin{tabular}{|c|c|c|c|c|c|}
\hline Rice & Cas9 & $\begin{array}{l}\text { Thermogenic male } \\
\text { sterility }\end{array}$ & Indel & OsTms5, OsPi21, OsXa13 & 8 \\
\hline Rice & Cpf1 & - & Indel & OsPDS, OsGS3 & 168 \\
\hline Rice & Cas90 & Agronomic Parameters & Indel & OsGS3, OsGW2 and OsGnla & 55 \\
\hline Rice & Cas9 & $\begin{array}{l}\text { Serine/Arginine gene } \\
\text { family }\end{array}$ & Indel & $\begin{array}{l}\text { SR32, SR33a, SR33, and SR40, } \\
\text { SZ21a, RSZ21, RSZ23, SC25, } \\
\text { SC32, SC34, SCL25, SCL26, } \\
\text { SCL28, SCL30a, SCL30, } \\
\text { SCL57S2Z36, RS2Z37, RS2Z38, } \\
\text { RS2Z39, RS29, RS-33 }\end{array}$ & 169 \\
\hline Rice & $\begin{array}{l}\text { AsCas } 12 \mathrm{a}, \\
\text { FnCas } 12 \mathrm{a}, \\
\text { and } \\
\text { LbCas } 12 \mathrm{a}\end{array}$ & Temperature sensitivity & Indel & OsROC5 and OsDEP1 & 170 \\
\hline Rice & Cas9 & Dropping leaf & Indel & Multiple sites of OsDl & 171 \\
\hline Tomato & Cpf1 & - & Indel & Multiple target sites of SIMYB12 & 172 \\
\hline $\begin{array}{l}\text { Arabidopsis } \\
\text { thaliana }\end{array}$ & Cpf1 & - & Indel & Multiple target sites of AtPDS3 & 172 \\
\hline
\end{tabular}




\begin{tabular}{|c|c|c|c|c|c|}
\hline $\begin{array}{l}\text { Arabidopsis } \\
\text { thaliana }\end{array}$ & Cas9 & - & Indel & Five sites in PTOX locus & 173 \\
\hline $\begin{array}{l}\text { Arabidopsis } \\
\text { thaliana }\end{array}$ & $\mathrm{LbCas} 12 \mathrm{a}$ & Temperature sensitivity & Indel & AtGLABRA2,At TT4 & 170 \\
\hline N. benthamiana & Cpf1 & - & Indel & Multiple target sites of $\mathrm{Nb} \mathrm{XT} 1$ & 172 \\
\hline $\begin{array}{l}\text { Nicotiana } \\
\text { benthamiana }\end{array}$ & Cas9 & - & Indel & XylT and FucT & 174 \\
\hline Tobacco & $\begin{array}{l}\text { Cas9 and } \\
\text { Cpf1 }\end{array}$ & $\begin{array}{l}\text { Homozygous multiplex } \\
\text { genome editing in } \\
\text { polyploid }\end{array}$ & Indel & PDS, ETR1 & 175 \\
\hline Brassica campestris & Cas9 & - & Indel & $\begin{array}{l}\text { Bra003491, Bra007665, and } \\
\text { Bra014410 }\end{array}$ & 176 \\
\hline Maize & $\mathrm{LbCas} 12 \mathrm{a}$ & Temperature sensitivity & Indel & Multiple sites in PAP1 & 170 \\
\hline Maize & $\begin{array}{l}\text { Cas9 and } \\
\text { Cpf1 }\end{array}$ & Epicuticle Wax & Indel & Multiple Sites of Gloassy 2 & 177 \\
\hline $\begin{array}{l}\text { Arabidopsis } \\
\text { thaliana }\end{array}$ & Cas9 & $\begin{array}{l}\text { Floral organ } \\
\text { development }\end{array}$ & Indel & AP1, SVP, TFL1 & 178 \\
\hline Citrus & Cas9 & Citrus Canker & Indel & Multiple sites of CsLOB1 & 179 \\
\hline
\end{tabular}




\begin{tabular}{|c|c|c|c|c|c|}
\hline Carrots & Cas9 & Albino carrots & Indel & DcPDS, DcMYB113 & 180 \\
\hline Banana & Cas9 & Bacterial Blight & Indel & $\begin{array}{l}\text { OsSWEET11, OsSWEET13 } \\
\text { OsSWEET14 }\end{array}$ & 181 \\
\hline Wheat & Cas9 & - & Indel & TaDA1, TaPDS, TaNCED1 & 155 \\
\hline Soybean & Cas9 & Soybean mosaic virus & Indel & GmF3H1, GmF3H2, GmFNSII-1 & 26 \\
\hline Rice & Cas9 & Agronomic traits & Indel & OsGW7, OsER1 & 182 \\
\hline Rice & Cas9 & Agronomic traits & Indel & PDS, RDR6, SGS3, & 183 \\
\hline Rice & Cas9 & Cytosine base editing & Indel & $\begin{array}{l}\text { OsPDS, OsWaxy, OsGRF4, } \\
\text { OsALS, OsMPK5, OsNRT1.1B, } \\
\text { OsMPK2, }\end{array}$ & 184 \\
\hline Rice & Cas9 & $\begin{array}{l}\text { Dwarf and increased } \\
\text { tillering }\end{array}$ & Indel & OsDWARF14 and OsCCD8 & 185 \\
\hline Rice & Cas9 & Protein kinases & Indel & OsMPK14, OsMPK15 & 186 \\
\hline Glycine max & Cas9 & - & Indel & GmRIC1, GmRIC2 & 187 \\
\hline
\end{tabular}




\begin{tabular}{|l|l|l|l|l|l|}
\hline Citrus & Cas9 & - & Indel & Multiple site of CsLOB1 & 188 \\
\hline Durum wheat & Cas9 & Reduce Allergen Proteins & Indel & CM3, CM16 & 86 \\
\hline N. benthamiana & Cas9 & - & Indel & Multiple sites of PDS3 & 189 \\
\hline $\begin{array}{l}\text { Medicago sativa } \\
\text { Soybean }\end{array}$ & Cas9 & Stay Green Trait & Indel & Multiple sites of MsSGR & 190 \\
\hline $\begin{array}{l}\text { Arabidopsis } \\
\text { thaliana }\end{array}$ & Cas9 & Flowering time & Indel & Multiple sites of LNK2 \\
\hline $\begin{array}{l}\text { Arabidopsis } \\
\text { thaliana }\end{array}$ & Cas9 & - & Indel & BRI1, BZR1, BES1 & 192 \\
\hline
\end{tabular}


46 Table S6. Regulatory frameworks of different countries for CRISPR—biosafety legislation, regulators, status of legislation, salient

47 features, and regulatory requirements for commercial cultivation or use of final products.

\begin{tabular}{|c|c|c|c|c|c|c|c|}
\hline $\begin{array}{l}\text { Current status of } \\
\text { legislation }\end{array}$ & Country & Regulating body & $\begin{array}{l}\text { Main } \\
\text { legislation }\end{array}$ & $\begin{array}{l}\text { Framework or specific } \\
\text { law (for env. release) }\end{array}$ & $\begin{array}{l}\text { Regulatory } \\
\text { trigger' }\end{array}$ & $\begin{array}{l}\text { Regulatory } \\
\text { requirements for } \\
\text { unconfined } \\
\text { environmental release }\end{array}$ & $\begin{array}{l}\text { Authorization } \\
\text { period (for } \\
\text { marketing) }\end{array}$ \\
\hline \multirow{3}{*}{$\begin{array}{l}\text { Genome-edited } \\
\text { crops are not } \\
\text { regulated as } \\
\text { GMOs }\end{array}$} & U.S.A & $\begin{array}{l}\text { USDA, APHIS, } \\
\text { FDA and EPA }\end{array}$ & $\begin{array}{l}\text { Co-ordinated framework } \\
\text { for the regulation of } \\
\text { biotechnology (1986) }\end{array}$ & $\begin{array}{l}\text { Framework refers to } \\
\text { relevant sectoral } \\
\text { legislation (e.g. Plant } \\
\text { Protection Act, Federal } \\
\text { Insecticide, Fungicide, } \\
\text { and Rodenticide Act. } \\
\text { Toxic Substances } \\
\text { Control Act) }\end{array}$ & $\begin{array}{l}\text { Product- } \\
\text { based (risk- } \\
\text { based) }\end{array}$ & Risk assessment & $\begin{array}{l}\text { Not fruited } \\
\text { (possibility of } \\
\text { revocation) }\end{array}$ \\
\hline & Canada & CFIA & $\begin{array}{l}\text { Regulatory Framework } \\
\text { for Biotechnology (1993) }\end{array}$ & $\begin{array}{l}\text { Framework includes } \\
\text { regulations for plants } \\
\text { with novel traits and } \\
\text { novel foods and feeds }\end{array}$ & $\begin{array}{l}\text { Product- } \\
\text { based } \\
\text { (novelty- } \\
\text { and risk- } \\
\text { based) }\end{array}$ & $\begin{array}{l}\text { Risk assessment, } \\
\text { stewardship (risk } \\
\text { management) }\end{array}$ & $\begin{array}{l}\text { Not fruited } \\
\text { (possibility of } \\
\text { revocation) }\end{array}$ \\
\hline & Argentina & CONABIA & $\begin{array}{ll}\text { Regulation } & \text { Framework } \\
\text { for } & \text { Agricultural }\end{array}$ & $\begin{array}{l}\text { Supplementary } \\
\text { Resolution for release }\end{array}$ & $\begin{array}{l}\text { Process- } \\
\text { based }\end{array}$ & $\begin{array}{l}\text { Risk assessment, socio- } \\
\text { economic }\end{array}$ & $\begin{array}{l}\text { Not fruited, } \\
\text { (possibility of }\end{array}$ \\
\hline
\end{tabular}




\begin{tabular}{|c|c|c|c|c|c|c|}
\hline & & Biotechnology (1991) & of GMOs & & considerations & revocation) \\
\hline Brazil & CTNBio & $\begin{array}{l}\text { Biosafety law (1995: } \\
\text { updated 2005) }\end{array}$ & $\begin{array}{lr}\text { Biosafety } & \text { Law } \\
\text { supplemented } & \text { by } \\
\text { implementing } & \\
\text { Resolutions } & \end{array}$ & $\begin{array}{l}\text { Process- } \\
\text { based }\end{array}$ & $\begin{array}{l}\text { Risk assessment, } \\
\text { coexistence, } \\
\text { monitoring, labeling, } \\
\text { optional socio economic } \\
\text { considerations }\end{array}$ & $\begin{array}{l}\text { Not fruited } \\
\text { (possibility of } \\
\text { revocation) }\end{array}$ \\
\hline Australia & OGTR & $\begin{array}{l}\text { Gene Technology Act } \\
(2000) \text {. Food Standards } \\
\text { Australia New Zealand } \\
\text { Act (1991) }\end{array}$ & $\begin{array}{l}\text { Supplementary } \\
\text { Regulations e.g., Gene } \\
\text { Technology Regulation } \\
(2001)\end{array}$ & $\begin{array}{l}\text { Process- } \\
\text { based }\end{array}$ & $\begin{array}{ll}\text { Risk assessment, } & \text { risk } \\
\text { management } & \text { and } \\
\text { monitoring } & \end{array}$ & $\begin{array}{l}\text { Not fruited, } \\
\text { (possibility of } \\
\text { revocation) }\end{array}$ \\
\hline South Africa & MoAFF & GMO Act (1997) & $\begin{array}{l}\text { GMO Regulations } \\
\text { (amended in 2010) }\end{array}$ & $\begin{array}{l}\text { Process- } \\
\text { based }\end{array}$ & $\begin{array}{lr}\text { Risk } & \text { assessment, } \\
\text { monitoring, labeling, } \\
\text { detection } \\
\text { optional methods, } \\
\text { economic } \\
\text { considerations }\end{array}$ & $\begin{array}{l}\text { Not fruited } \\
\text { (possibility of } \\
\text { revocation) }\end{array}$ \\
\hline Japan & $\begin{array}{l}\text { Ministry of } \\
\text { Environment }\end{array}$ & $\begin{array}{l}\text { Cartagena Act } \\
\text { established in 2003, and } \\
\text { modified and updated in } \\
2019\end{array}$ & $\begin{array}{l}\text { Amended Cartagena } \\
\text { Act regarding new } \\
\text { genome editing } \\
\text { techniques in } 2019\end{array}$ & $\begin{array}{l}\text { Product- } \\
\text { based }\end{array}$ & $\begin{array}{lr}\text { Risk assessment, } \\
\text { labeling, } \\
\text { management } \\
\text { monitoring }\end{array}$ & $?$ \\
\hline
\end{tabular}




\begin{tabular}{|c|c|c|c|c|c|c|c|}
\hline \multirow[b]{2}{*}{$\begin{array}{l}\text { Discussion is } \\
\text { ongoing }\end{array}$} & UK & $\begin{array}{l}\text { Department for } \\
\text { Environment } \\
\text { Food and Rural } \\
\text { Affairs }\end{array}$ & $\begin{array}{l}\text { Biosafety Directives and } \\
\text { Regulations (food/feed. } \\
\text { env. release) (1990. } \\
\text { updated 2001/2003) }\end{array}$ & $\begin{array}{l}\text { Dir 2001/18/EC. } \\
\text { supplemented by } \\
\text { implementing } \\
\text { regulations and GM } \\
\text { food and feed } \\
\text { regulation (2003) }\end{array}$ & $\begin{array}{l}\text { Process- } \\
\text { based }\end{array}$ & $\begin{array}{l}\text { Risk assessment, risk } \\
\text { management, } \\
\text { coexistence, monitoring } \\
\text { labeling, detection } \\
\text { methods }\end{array}$ & $\begin{array}{l}10 \text { years, } \\
\text { renewable }\end{array}$ \\
\hline & Norway & ? & $\begin{array}{l}\text { Gene Technology Act } \\
\text { (1993) }\end{array}$ & $\begin{array}{l}\text { Regulations for risk } \\
\text { assessment }\end{array}$ & $\begin{array}{l}\text { Process- } \\
\text { based }\end{array}$ & $\begin{array}{l}\text { Risk assessment, risk } \\
\text { management, } \\
\text { monitoring, labeling, } \\
\text { detection methods, } \\
\text { socio- } \\
\text { economic/sustainability } \\
\text { assessment }\end{array}$ & $\begin{array}{l}10 \text { years, } \\
\text { renewable }\end{array}$ \\
\hline
\end{tabular}




\begin{tabular}{|c|c|c|c|c|c|c|c|}
\hline & & $\begin{array}{l}\text { Engineering } \\
\text { Approval } \\
\text { Committee }\end{array}$ & $\begin{array}{l}\text { 1989) notified under the } \\
\text { Environment } 194 \text { Act, } \\
1986\end{array}$ & $\begin{array}{l}\text { the protection and } \\
\text { improvement to the } \\
\text { environment. }\end{array}$ & & & \\
\hline \multirow{3}{*}{\begin{tabular}{l}
\multicolumn{2}{l}{ Genome-edited } \\
crops are \\
regulated as \\
GMOs
\end{tabular}} & $\begin{array}{l}\text { European } \\
\text { Union }\end{array}$ & EFSA & $\begin{array}{l}\text { Biosafety Directives and } \\
\text { Regulations (food/feed. } \\
\text { env. release) (1990. } \\
\text { updated 2001/2003) }\end{array}$ & $\begin{array}{l}\text { Dir 2001/18/EC. } \\
\text { supplemented by } \\
\text { implementing } \\
\text { regulations and } \text { GM } \\
\text { food and feed } \\
\text { regulation (2003) }\end{array}$ & $\begin{array}{l}\text { Process- } \\
\text { based }\end{array}$ & $\begin{array}{l}\text { Risk assessment, risk } \\
\text { management, } \\
\text { coexistence, monitoring } \\
\text { labeling, detection } \\
\text { methods }\end{array}$ & $\begin{array}{l}10 \text { years, } \\
\text { renewable }\end{array}$ \\
\hline & New Zealand & EPA & $\begin{array}{l}\text { Hazardous Substances } \\
\text { and New Organisms Act } \\
\text { (1996), Food Standards } \\
\text { Australia New Zealand } \\
\text { Act (1991) }\end{array}$ & $\begin{array}{l}\text { Supplementary } \\
\text { Regulations } \\
\text { 2003) and Methodology } \\
\text { Order (1998) }\end{array}$ & $\begin{array}{l}\text { Process- } \\
\text { based }\end{array}$ & $\begin{array}{l}\text { Risk assessment, risk } \\
\text { management, } \\
\text { monitoring (for } \\
\text { conditional releases) }\end{array}$ & $\begin{array}{l}\text { Not fruited } \\
\text { (possibility of } \\
\text { revocation) }\end{array}$ \\
\hline & Switzerland & FSVO, EFSA & $\begin{array}{l}\text { Gene Technology Act } \\
(2003)\end{array}$ & $\begin{array}{l}\text { Release Ordinance } \\
(2008)\end{array}$ & $\begin{array}{l}\text { Process- } \\
\text { based }\end{array}$ & $\begin{array}{l}\text { Risk assessment, } \\
\text { monitoring, labeling, } \\
\text { detection methods }\end{array}$ & $\begin{array}{l}10 \text { years, } \\
\text { renewable }\end{array}$ \\
\hline $\begin{array}{lr}\text { GMO-if } & \text { final } \\
\text { product } & \text { is } \\
\text { transgene } & \end{array}$ & China & $\begin{array}{l}\text { Office of } \\
\text { Agricultural } \\
\text { Genetic }\end{array}$ & $\begin{array}{l}\text { Regulation on protection } \\
\text { of new varieties of plants } \\
\text { issued by the state }\end{array}$ & $\begin{array}{l}\text { The food safety Law in } \\
2009 \text {, revised in } 2015 \text {. } \\
\text { Production and }\end{array}$ & $\begin{array}{l}\text { Process- } \\
\text { based }\end{array}$ & $\begin{array}{l}\text { Risk assessment, risk } \\
\text { management, } \\
\text { coexistence, monitoring }\end{array}$ & $\begin{array}{l}\text { 4-5 years more } \\
\text { than USA and } \\
\text { Canada }\end{array}$ \\
\hline
\end{tabular}




\begin{tabular}{|c|c|c|c|c|c|c|}
\hline & $\begin{array}{l}\text { Engineering } \\
\text { Biosafety } \\
\text { Administration, } \\
\text { and China Food } \\
\text { and Drug } \\
\text { Administration }\end{array}$ & $\begin{array}{l}\text { council (1997, revised in } \\
2013 \text { ) }\end{array}$ & $\begin{array}{l}\text { distribution of GM food } \\
\text { shall be clearly labeled }\end{array}$ & & $\begin{array}{l}\text { labeling, detection } \\
\text { methods }\end{array}$ & \\
\hline Pakistan & $\begin{array}{l}\text { The Ministry of } \\
\text { Environment }\end{array}$ & $\begin{array}{l}\text { Developed the Cartagena } \\
\text { Protocol in January } 2000 \\
\text { and enforced it on 11th } \\
\text { of September } 2003 \text {. }\end{array}$ & $\begin{array}{l}\text { The Ministry of } \\
\text { Environment of } \\
\text { Pakistan exercising the } \\
\text { powers of section } 31 \text { of } \\
\text { Pakistan Environment } \\
\text { Protection Act (1997) } \\
\text { framed the Pakistan } \\
\text { Biosafety Rules 2005 } \\
\text { and implemented them } \\
\text { in April 2005. }\end{array}$ & $\begin{array}{l}\text { Process- } \\
\text { based }\end{array}$ & $\begin{array}{ll}\text { Risk assessment, } & \text { risk } \\
\text { management } & \text { and } \\
\text { monitoring } & \end{array}$ & ? \\
\hline
\end{tabular}

48 Note: In different nations, different regulators and criteria have been used to regulate CRISPR-based genome-edited plants. Many countries have

49 excluded edited plants from GMO legislation due to the absence of any foreign particle, whereas few nations still consider edited plants as

50 GMOs. The assessment of edited plants is based on the end product or the process used. GMO: Genetically modified organism, USDA-APHIS:

51 US Department of Agriculture-Animal and Plant Health Inspection Service, CFIA: Canadian Food Inspection Agency, FDA: The Food and

52 Drug Administration, EPA: The Environmental Protection Agency, CFIA: Canadian Food Inspection Agency, CONABIA: National

53 Commission Advisor in Agricultural Biotechnology, CTNBio: Brazilian National Biosafety Technical Commission, OGTR: Office of the Gene 


\section{References}

1. FAO. FAOSTAT Online Database; Rome, Italy. 2020.

2. Li, C.; Li, W.; Zhou, Z.; Chen, H.; Xie, C.; Lin, Y. A new rice breeding method: CRISPR/Cas9 system editing of the Xa13 promoter to cultivate transgene-free bacterial blight-resistant rice. Plant Biotechnol. J. 2020, 18 (2), 313.

3. Zhou, J.; Peng, Z.; Long, J.; Sosso, D.; Liu, B.; Eom, J. S.; Huang, S.; Liu, S.; Vera Cruz, C.; Frommer, W. B. Gene targeting by the TAL effector PthXo2 reveals cryptic resistance gene for bacterial blight of rice. Plant J. 2015, 82 (4), 632-643.

4. Zeng, X.; Luo, Y.; Vu, N. T. Q.; Shen, S.; Xia, K.; Zhang, M. CRISPR/Cas9mediated mutation of OsSWEET14 in rice cv. Zhonghua11 confers resistance to Xanthomonas oryzae pv. oryzae without yield penalty. BMC Plant Biol. 2020, 20 (1), 1-11.

5. Zafar, K.; Khan, M. Z.; Amin, I.; Mukhtar, Z.; Yasmin, S.; Arif, M.; Ejaz, K.; Mansoor, S. Precise CRISPR-Cas9 mediated genome editing in super basmati rice for resistance against bacterial blight by targeting the major susceptibility gene. Front. Plant Sci. 2020, $11,575$.

6. Wang, F.; Wang, C.; Liu, P.; Lei, C.; Hao, W.; Gao, Y.; Liu, Y.-G.; Zhao, K. Enhanced rice blast resistance by CRISPR/Cas9-targeted mutagenesis of the ERF transcription factor gene OsERF922. PLoS One 2016, 11 (4), e0154027.

7. Nawaz, G.; Usman, B.; Peng, H.; Zhao, N.; Yuan, R.; Liu, Y.; Li, R. Knockout of Pi21 by CRISPR/Cas9 and iTRAQ-Based Proteomic Analysis of Mutants Revealed New Insights into M. oryzae Resistance in Elite Rice Line. Genes 2020, 11 (7), 735.

8. $\quad$ Li, S.; Shen, L.; Hu, P.; Liu, Q.; Zhu, X.; Qian, Q.; Wang, K.; Wang, Y. Developing disease-resistant thermosensitive male sterile rice by multiplex gene editing. $J$. Integr. Plant Biol. 2019, 61 (12), 1201-1205.

9. Foster, A. J.; Martin-Urdiroz, M.; Yan, X.; Wright, H. S.; Soanes, D. M.; Talbot, N. J. CRISPR-Cas9 ribonucleoprotein-mediated co-editing and counterselection in the rice blast fungus. Sci. Rep. 2018, 8 (1), 1-12.

10. Liang, Y.; Han, Y.; Wang, C.; Jiang, C.; Xu, J.-R. Targeted deletion of the USTA and UvSLT2 genes efficiently in Ustilaginoidea virens with the CRISPR-Cas9 system. Front. Plant Sci. 2018, 9, 699.

11. Macovei, A.; Sevilla, N. R.; Cantos, C.; Jonson, G. B.; Slamet-Loedin, I.; Čermák, T.; Voytas, D. F.; Choi, I. R.; Chadha-Mohanty, P. Novel alleles of rice eIF4G generated by CRISPR/Cas9-targeted mutagenesis confer resistance to Rice tungro spherical virus. Plant Biotechnol. J. 2018, 16 (11), 1918-1927. 
12. Wang, Y.; Cheng, X.; Shan, Q.; Zhang, Y.; Liu, J.; Gao, C.; Qiu, J.-L. Simultaneous editing of three homoeoalleles in hexaploid bread wheat confers heritable resistance to powdery mildew. Nat. Biotechnol. 2014, 32 (9), 947-951.

13. Zhang, Y.; Bai, Y.; Wu, G.; Zou, S.; Chen, Y.; Gao, C.; Tang, D. Simultaneous modification of three homoeologs of Ta EDR 1 by genome editing enhances powdery mildew resistance in wheat. Plant J. 2017, 91 (4), 714-724.

14. Kis, A.; Hamar, É.; Tholt, G.; Bán, R.; Havelda, Z. Creating highly efficient resistance against wheat dwarf virus in barley by employing CRISPR/Cas9 system. Plant Biotechnol. J. 2019, 17 (6), 1004.

15. de Toledo Thomazella, D. P.; Brail, Q.; Dahlbeck, D.; Staskawicz, B. CRISPR-Cas9 mediated mutagenesis of a DMR6 ortholog in tomato confers broad-spectrum disease resistance. BioRxiv 2016, 064824.

16. Ortigosa, A.; Gimenez-Ibanez, S.; Leonhardt, N.; Solano, R. Design of a bacterial speck resistant tomato by CRISPR/Cas9-mediated editing of S1 JAZ 2. Plant Biotechnol. J. 2019, 17 (3), 665-673.

17. Nekrasov, V.; Wang, C.; Win, J.; Lanz, C.; Weigel, D.; Kamoun, S. Rapid generation of a transgene-free powdery mildew resistant tomato by genome deletion. Sci. Rep. 2017, 7 (1), 1-6.

18. Koseoglou, E. The study of SIPMR4 CRISPR/Cas9-mediated tomato allelic series for resistance against powdery mildew. Master thesis, Wageningen University and Research, Wageningen, 2017.

19. Shu, P.; Li, Z.; Min, D.; Zhang, X.; Ai, W.; Li, J.; Zhou, J.; Li, Z.; Li, F.; Li, X. CRISPR/Cas9-Mediated SIMYC2 Mutagenesis Adverse to Tomato Plant Growth and MeJAInduced Fruit Resistance to Botrytis cinerea. J. Agric. Food Chem. 2020, 68 (20), 5529-5538.

20. Tashkandi, M.; Ali, Z.; Aljedaani, F.; Shami, A.; Mahfouz, M. M. Engineering resistance against Tomato yellow leaf curl virus via the CRISPR/Cas9 system in tomato. Plant Signal. Behav. 2018, 13 (10), e1525996.

21. Wang, Z.; Hardcastle, T. J.; Pastor, A. C.; Yip, W. H.; Tang, S.; Baulcombe, D. C. A novel DCL2-dependent miRNA pathway in tomato affects susceptibility to RNA viruses. Genes Dev. 2018, 32 (17-18), 1155-1160.

22. Wang, T.; Deng, Z.; Zhang, X.; Wang, H.; Wang, Y.; Liu, X.; Liu, S.; Xu, F.; Li, T.; Fu, D. Tomato DCL2b is required for the biosynthesis of 22-nt small RNAs, the resulting secondary siRNAs, and the host defense against ToMV. Hortic. Res. 2018, 5 (1), 1-14.

23. Yoon, Y.-J.; Venkatesh, J.; Lee, J.-H.; Kim, J.; Lee, H.-E.; Kim, D.-S.; Kang, B.C. Genome Editing of eIF4E1 in Tomato Confers Resistance to Pepper Mottle Virus. Front. Plant Sci. 2020, 11, 1098. 
24. Faal, P. G.; Farsi, M.; Seifi, A.; Kakhki, A. M. Virus-induced CRISPR-Cas9 system improved resistance against tomato yellow leaf curl virus. Mol. Biol. Rep. 2020, 47 (5), 33693376.

25. Chandrasekaran, J.; Brumin, M.; Wolf, D.; Leibman, D.; Klap, C.; Pearlsman, M.; Sherman, A.; Arazi, T.; Gal-On, A. Development of broad virus resistance in non-transgenic cucumber using CRISPR/Cas9 technology. Mol. Plant Pathol. 2016, 17 (7), 1140-1153.

26. Zhang, P.; Du, H.; Wang, J.; Pu, Y.; Yang, C.; Yan, R.; Yang, H.; Cheng, H.; Yu, D. Multiplex CRISPR/Cas9-mediated metabolic engineering increases soya bean isoflavone content and resistance to soya bean mosaic virus. Plant Biotechnol. J. 2020, 18 (6), 13841395.

27. Huang, X.; Zeng, X.; Li, J.; Zhao, D. Construction and analysis of tifyla and tify1b mutants in rice (Oryza sativa) based on CRISPR/Cas9 technology. J. Agric. Biotech. 2017, 25 (6), 1003-1012.

28. Zeng, Y.; Wen, J.; Zhao, W.; Wang, Q.; Huang, W. Rational Improvement of Rice Yield and Cold Tolerance by Editing the Three Genes OsPIN5b, GS3, and OsMYB30 With the CRISPR-Cas9 System. Front. Plant Sci. 2020, 10, 1663.

29. Santosh Kumar, V.; Verma, R. K.; Yadav, S. K.; Yadav, P.; Watts, A.; Rao, M.; Chinnusamy, V. CRISPR-Cas9 mediated genome editing of drought and salt tolerance (OsDST) gene in indica mega rice cultivar MTU1010. Physiol. Mol. Biol. Plants 2020, 26, 1099-1110.

30. Zhang, Y.; Li, J.; Chen, S.; Ma, X.; Wei, H.; Chen, C.; Gao, N.; Zou, Y.; Kong, D.; Li, T. An APETALA2/ethylene responsive factor, OsEBP89 knockout enhances adaptation to direct-seeding on wet land and tolerance to drought stress in rice. Mol. Genet. Genomics 2020, 295 (4), 941-956.

31. Lou, D.; Wang, H.; Liang, G.; Yu, D. OsSAPK2 confers abscisic acid sensitivity and tolerance to drought stress in rice. Front. Plant Sci. 2017, 8, 993.

32. Liao, S.; Qin, X.; Luo, L.; Han, Y.; Wang, X.; Usman, B.; Nawaz, G.; Zhao, N.; Liu, Y.; Li, R. CRISPR/Cas9-Induced Mutagenesis of Semi-Rolled Leaf1, 2 Confers Curled Leaf Phenotype and Drought Tolerance by Influencing Protein Expression Patterns and ROS Scavenging in Rice (Oryza sativa L.). Agronomy 2019, 9 (11), 728.

33. Zhang, A.; Liu, Y.; Wang, F.; Li, T.; Chen, Z.; Kong, D.; Bi, J.; Zhang, F.; Luo, X.; Wang, J. Enhanced rice salinity tolerance via CRISPR/Cas9-targeted mutagenesis of the OsRR22 gene. Mol. Breed. 2019, 39 (3), 1-10.

34. Kitomi, Y.; Hanzawa, E.; Kuya, N.; Inoue, H.; Hara, N.; Kawai, S.; Kanno, N.; Endo, M.; Sugimoto, K.; Yamazaki, T. Root angle modifications by the DRO1 homolog improve rice yields in saline paddy fields. Proc. Natl. Acad. Sci. U.S.A. 2020, 117 (35), 21242-21250. 
35. Tang, L.; Mao, B.; Li, Y.; Lv, Q.; Zhang, L.; Chen, C.; He, H.; Wang, W.; Zeng, X.; Shao, Y. Knockout of OsNramp5 using the CRISPR/Cas9 system produces low Cdaccumulating indica rice without compromising yield. Sci. Rep. 2017, 7 (1), 1-12.

36. Songmei, L.; Jie, J.; Yang, L.; Jun, M.; Shouling, X.; Yuanyuan, T.; Youfa, L.; Qingyao, S.; Jianzhong, H. Characterization and evaluation of OsLCT1 and OsNramp5 mutants generated through CRISPR/Cas9-mediated mutagenesis for breeding low Cd rice. Rice Sci. 2019, 26 (2), 88-97.

37. YANG, C.-H.; ZHANG, Y.; HUANG, C.-F. Reduction in cadmium accumulation in japonica rice grains by CRISPR/Cas9-mediated editing of OsNRAMP5. J. Integr. Agric. 2019, 18 (3), 688-697.

38. Zhang, R.; Gao, C. Generating herbicide tolerance in rice by base editing. Sci. China Life Sci. 2020.

39. Wang, F.; Xu, Y.; Li, W.; Chen, Z.; Wang, J.; Fan, F.; Tao, Y.; Jiang, Y.; Zhu, Q.-H.; Yang, J. Creating a novel herbicide-tolerance OsALS allele using CRISPR/Cas9mediated gene editing. Crop J. 2020.

40. Butt, H.; Rao, G. S.; Sedeek, K.; Aman, R.; Kamel, R.; Mahfouz, M. Engineering herbicide resistance via prime editing in rice. Plant Biotechnol. J. 2020, 18 (12), 2370-2372.

41. Kuang, Y.; Li, S.; Ren, B.; Yan, F.; Spetz, C.; Li, X.; Zhou, X.; Zhou, H. Baseediting-mediated artificial evolution of OsALS1 in planta to develop novel herbicide-tolerant rice germplasms. Mol Plant. 2020, 13 (4), 565-572.

42. Li, S.; Li, J.; He, Y.; Xu, M.; Zhang, J.; Du, W.; Zhao, Y.; Xia, L. Precise gene replacement in rice by RNA transcript-templated homologous recombination. Nat. Biotechnol. 2019, 37 (4), 445-450.

43. Sun, Y.; Zhang, X.; Wu, C.; He, Y.; Ma, Y.; Hou, H.; Guo, X.; Du, W.; Zhao, Y.; Xia, L. Engineering herbicide-resistant rice plants through CRISPR/Cas9-mediated homologous recombination of acetolactate synthase. Mol Plant. 2016, 9 (4), 628-631.

44. Shi, J.; Gao, H.; Wang, H.; Lafitte, H. R.; Archibald, R. L.; Yang, M.; Hakimi, S. M.; Mo, H.; Habben, J. E. ARGOS 8 variants generated by CRISPR-Cas9 improve maize grain yield under field drought stress conditions. Plant Biotechnol. J. 2017, 15 (2), 207-216.

45. Jiang, Y.-Y.; Chai, Y.-P.; Lu, M.-H.; Han, X.-L.; Lin, Q.; Zhang, Y.; Zhang, Q.; Zhou, Y.; Wang, X.-C.; Gao, C. Prime editing efficiently generates W542L and S621I double mutations in two ALS genes in maize. Genome Biol. 2020, 21 (1), 1-10.

46. Li, Y.; Zhu, J.; Wu, H.; Liu, C.; Huang, C.; Lan, J.; Zhao, Y.; Xie, C. Precise base editing of non-allelic acetolactate synthase genes confers sulfonylurea herbicide resistance in maize. Crop J. 2020, 8 (3), 449-456. 
47. Svitashev, S.; Young, J. K.; Schwartz, C.; Gao, H.; Falco, S. C.; Cigan, A. M. Targeted mutagenesis, precise gene editing, and site-specific gene insertion in maize using Cas9 and guide RNA. Plant Physiol. 2015, 169 (2), 931-945.

48. Yu, W.; Wang, L.; Zhao, R.; Sheng, J.; Zhang, S.; Li, R.; Shen, L. Knockout of SIMAPK3 enhances tolerance to heat stress involving ROS homeostasis in tomato plants. BMC Plant Biol. 2019, 19 (1), 1-13.

49. Klap, C.; Yeshayahou, E.; Bolger, A. M.; Arazi, T.; Gupta, S. K.; Shabtai, S.; Usadel, B.; Salts, Y.; Barg, R. Tomato facultative parthenocarpy results from S1 AGAMOUS-LIKE 6 loss of function. Plant Biotechnol. J. 2017, 15 (5), 634-647.

50. Bouzroud, S.; Gasparini, K.; Hu, G.; Barbosa, M. A. M.; Rosa, B. L.; Fahr, M.; Bendaou, N.; Bouzayen, M.; Zsögön, A.; Smouni, A. Down regulation and loss of auxin response factor 4 function using CRISPR/Cas9 alters plant growth, stomatal function and improves tomato tolerance to salinity and osmotic stress. Genes 2020, 11 (3), 272.

51. Danilo, B.; Perrot, L.; Mara, K.; Botton, E.; Nogué, F.; Mazier, M. Efficient and transgene-free gene targeting using Agrobacterium-mediated delivery of the CRISPR/Cas9 system in tomato. Plant Cell Rep. 2019, 38 (4), 459-462.

52. Wu, J.; Chen, C.; Xian, G.; Liu, D.; Lin, L.; Yin, S.; Sun, Q.; Fang, Y.; Zhang, H.; Wang, Y. Engineering herbicide-resistant oilseed rape by CRISPR/Cas9-mediated cytosine base-editing. Plant Biotechnol. J. 2020, 18 (9), 1857-1859.

53. Badhan, S.; Ball, A. S.; Mantri, N. First Report of CRISPR/Cas9 Mediated DNAFree Editing of 4CL and RVE7 Genes in Chickpea Protoplasts. Int. J. Mol. Sci. 2021, 22 (1), 396.

54. Yuyu, C.; Aike, Z.; Pao, X.; Xiaoxia, W.; Yongrun, C.; Beifang, W.; Yue, Z.; Liaqat, S.; Shihua, C.; Liyong, C. Effects of GS3 and GL3. 1 for Grain Size Editing by CRISPR/Cas9 in Rice. Rice Sci. 2020, 27 (5), 405-413.

55. Zhou, J.; Xin, X.; He, Y.; Chen, H.; Li, Q.; Tang, X.; Zhong, Z.; Deng, K.; Zheng, X.; Akher, S. A. Multiplex QTL editing of grain-related genes improves yield in elite rice varieties. Plant Cell Rep. 2019, 38 (4), 475-485.

56. Liu, J.; Chen, J.; Zheng, X.; Wu, F.; Lin, Q.; Heng, Y.; Tian, P.; Cheng, Z.; Yu, X.; Zhou, K. GW5 acts in the brassinosteroid signalling pathway to regulate grain width and weight in rice. Nat. Plants 2017, 3 (5), 1-7.

57. Xu, R.; Yang, Y.; Qin, R.; Li, H.; Qiu, C.; Li, L.; Wei, P.; Yang, J. Rapid improvement of grain weight via highly efficient CRISPR/Cas9-mediated multiplex genome editing in rice. J. Genet. Genomics 2016, 43 (8), 529-532. 
58. Shen, L.; Wang, C.; Fu, Y.; Wang, J.; Liu, Q.; Zhang, X.; Yan, C.; Qian, Q.; Wang, K. QTL editing confers opposing yield performance in different rice varieties. $J$. Integr. Plant Biol. 2018, 60 (2), 89-93.

59. Miao, C.; Xiao, L.; Hua, K.; Zou, C.; Zhao, Y.; Bressan, R. A.; Zhu, J.-K. Mutations in a subfamily of abscisic acid receptor genes promote rice growth and productivity. Proc. Natl. Acad. Sci. U.S.A. 2018, 115 (23), 6058-6063.

60. Huang, L.; Zhang, R.; Huang, G.; Li, Y.; Melaku, G.; Zhang, S.; Chen, H.; Zhao, Y.; Zhang, J.; Zhang, Y. Developing superior alleles of yield genes in rice by artificial mutagenesis using the CRISPR/Cas9 system. Crop J. 2018, 6 (5), 475-481.

61. Wang, C.; Wang, G.; Gao, Y.; Lu, G.; Habben, J. E.; Mao, G.; Chen, G.; Wang, J.; Yang, F.; Zhao, X. A cytokinin-activation enzyme-like gene improves grain yield under various field conditions in rice. Plant Mol. Biol. 2020, 102 (4), 373-388.

62. Lu, K.; Wu, B.; Wang, J.; Zhu, W.; Nie, H.; Qian, J.; Huang, W.; Fang, Z. Blocking amino acid transporter Os AAP 3 improves grain yield by promoting outgrowth buds and increasing tiller number in rice. Plant Biotechnol. J. 2018, 16 (10), 1710-1722.

63. Ma, L.; Li, T.; Hao, C.; Wang, Y.; Chen, X.; Zhang, X. Ta GS 5-3A, a grain size gene selected during wheat improvement for larger kernel and yield. Plant Biotechnol. J. 2016, 14 (5), 1269-1280.

64. Zhang, Z.; Hua, L.; Gupta, A.; Tricoli, D.; Edwards, K. J.; Yang, B.; Li, W. Development of an Agrobacterium-delivered CRISPR/Cas9 system for wheat genome editing. Plant Biotechnol. J. 2019, 17 (8), 1623-1635.

65. Zhang, Y.; Li, D.; Zhang, D.; Zhao, X.; Cao, X.; Dong, L.; Liu, J.; Chen, K.; Zhang, H.; Gao, C. Analysis of the functions of Ta GW 2 homoeologs in wheat grain weight and protein content traits. Plant J. 2018, 94 (5), 857-866.

66. Zhang, Y.; Gao, C. Recent advances in DNA-free editing and precise base editing in plants. Emerging Top. Life Sci. 2017, 1 (2), 161-168.

67. Holubová, K.; Hensel, G.; Vojta, P.; Tarkowski, P.; Bergougnoux, V.; Galuszka, P. Modification of barley plant productivity through regulation of cytokinin content by reversegenetics approaches. Front. Plant Sci. 2018, 9, 1676.

68. Rodríguez-Leal, D.; Lemmon, Z. H.; Man, J.; Bartlett, M. E.; Lippman, Z. B. Engineering quantitative trait variation for crop improvement by genome editing. Cell 2017, 171 (2), 470-480. e8.

69. Yuste-Lisbona, F. J.; Fernández-Lozano, A.; Pineda, B.; Bretones, S.; OrtízAtienza, A.; García-Sogo, B.; Müller, N. A.; Angosto, T.; Capel, J.; Moreno, V. ENO regulates tomato fruit size through the floral meristem development network. Proc. Natl. Acad. Sci. U.S.A. 2020, 117 (14), 8187-8195. 
70. Wang, S.; Yang, Y.; Guo, M.; Zhong, C.; Yan, C.; Sun, S. Targeted mutagenesis of amino acid transporter genes for rice quality improvement using the CRISPR/Cas9 system. Crop J. 2020, 8 (3), 457-464.

71. Pérez, L.; Soto, E.; Villorbina, G.; Bassie, L.; Medina, V.; Muñoz, P.; Capell, T.; Zhu, C.; Christou, P.; Farré, G. CRISPR/Cas9-induced monoallelic mutations in the cytosolic AGPase large subunit gene APL2 induce the ectopic expression of APL2 and the corresponding small subunit gene APS2b in rice leaves. Transgenic Res. 2018, 27 (5), 423439.

72. Ma, X.; Zhang, Q.; Zhu, Q.; Liu, W.; Chen, Y.; Qiu, R.; Wang, B.; Yang, Z.; Li, H.; Lin, Y. A robust CRISPR/Cas9 system for convenient, high-efficiency multiplex genome editing in monocot and dicot plants. Mol Plant. 2015, 8 (8), 1274-1284.

73. Zhang, J.; Zhang, H.; Botella, J. R.; Zhu, J. K. Generation of new glutinous rice by CRISPR/Cas9-targeted mutagenesis of the Waxy gene in elite rice varieties. J. Integr. Plant Biol. 2018, 60 (5), 369-375.

74. Sun, Y.; Jiao, G.; Liu, Z.; Zhang, X.; Li, J.; Guo, X.; Du, W.; Du, J.; Francis, F.; Zhao, Y. Generation of high-amylose rice through CRISPR/Cas9-mediated targeted mutagenesis of starch branching enzymes. Front. Plant Sci. 2017, 8, 298.

75. Shufen, C.; Yicong, C.; Baobing, F.; Guiai, J.; Zhonghua, S.; Ju, L.; Shaoqing, T.; Jianlong, W.; Peisong, H.; Xiangin, W. Editing of rice isoamylase gene ISA1 provides insights into its function in starch formation. Rice Sci. 2019, 26 (2), 77-87.

76. Xu, Y.; Lin, Q.; Li, X.; Wang, F.; Chen, Z.; Wang, J.; Li, W.; Fan, F.; Tao, Y.; Jiang, Y. Fine-tuning the amylose content of rice by precise base editing of the Wx gene. Plant Biotechnol. J. 2021, 19 (1), 11.

77. Huang, L.; Li, Q.; Zhang, C.; Chu, R.; Gu, Z.; Tan, H.; Zhao, D.; Fan, X.; Liu, Q. Creating novel Wx alleles with fine-tuned amylose levels and improved grain quality in rice by promoter editing using CRISPR/Cas9 system. Plant Biotechnol. J. 2020, 18 (11), 21642166.

78. Zeng, D.; Liu, T.; Ma, X.; Wang, B.; Zheng, Z.; Zhang, Y.; Xie, X.; Yang, B.; Zhao, Z.; Zhu, Q. Quantitative regulation of Waxy expression by CRISPR/Cas9-based promoter and 5'UTR-intron editing improves grain quality in rice. Plant Biotechnol. J. 2020, 18 (12), 2385-2387.

79. Khan, M. S. S.; Basnet, R.; Ahmed, S.; Bao, J.; Shu, Q. Mutations of OsPLDa1 Increase Lysophospholipid Content and Enhance Cooking and Eating Quality in Rice. Plants 2020, 9 (3), 390.

80. Dong, O. X.; Yu, S.; Jain, R.; Zhang, N.; Duong, P. Q.; Butler, C.; Li, Y.; Lipzen, A.; Martin, J. A.; Barry, K. W. Marker-free carotenoid-enriched rice generated through targeted gene insertion using CRISPR-Cas9. Nat. Commun. 2020, 11 (1), 1-10. 
81. Abe, K.; Araki, E.; Suzuki, Y.; Toki, S.; Saika, H. Production of high oleic/low linoleic rice by genome editing. Plant Physiol. Biochem. 2018, 131, 58-62.

82. Khan, M. S. S.; Basnet, R.; Islam, S. A.; Shu, Q. Mutational analysis of OsPLD $\alpha 1$ reveals its involvement in phytic acid biosynthesis in rice grains. J. Agric. Food. Chem. 2019, 67 (41), 11436-11443.

83. Gao, H.; Gadlage, M. J.; Lafitte, H. R.; Lenderts, B.; Yang, M.; Schroder, M.; Farrell, J.; Snopek, K.; Peterson, D.; Feigenbutz, L. Superior field performance of waxy corn engineered using CRISPR-Cas9. Nat. Biotechnol. 2020, 38 (5), 579-581.

84. Veillet, F.; Chauvin, L.; Kermarrec, M.-P.; Sevestre, F.; Merrer, M.; Terret, Z.; Szydlowski, N.; Devaux, P.; Gallois, J.-L.; Chauvin, J.-E. The Solanum tuberosum GBSSI gene: a target for assessing gene and base editing in tetraploid potato. Plant Cell Rep. 2019, 38 (9), 1065-1080.

85. Wang, H.; Wu, Y.; Zhang, Y.; Yang, J.; Fan, W.; Zhang, H.; Zhao, S.; Yuan, L.; Zhang, P. CRISPR/Cas9-based mutagenesis of starch biosynthetic genes in sweet potato (Ipomoea Batatas) for the improvement of starch quality. Int. J. Mol. Sci. 2019, 20 (19), 4702.

86. Camerlengo, F.; Frittelli, A.; Sparks, C.; Doherty, A.; Martignago, D.; Larré, C.; Lupi, R.; Sestili, F.; Masci, S. CRISPR-Cas9 multiplex editing of the $\alpha$-amylase/trypsin inhibitor genes to reduce allergen proteins in durum wheat. Front. sustain. food syst. 2020, 4 , 104.

87. Lu, Y.; Zhu, J.-K. Precise editing of a target base in the rice genome using a modified CRISPR/Cas9 system. Mol Plant. 2017, 10 (3), 523-525.

88. Miao, C.; Wang, D.; He, R.; Liu, S.; Zhu, J. K. Mutations in MIR 396e and MIR $396 f$ increase grain size and modulate shoot architecture in rice. Plant Biotechnol. J. 2020, 18 (2), 491-501.

89. Shen, R.; Wang, L.; Liu, X.; Wu, J.; Jin, W.; Zhao, X.; Xie, X.; Zhu, Q.; Tang, H.; Li, Q. Genomic structural variation-mediated allelic suppression causes hybrid male sterility in rice. Nat. Commun. 2017, 8 (1), 1-10.

90. Xie, Y.; Xu, P.; Huang, J.; Ma, S.; Xie, X.; Tao, D.; Chen, L.; Liu, Y.-G. Interspecific hybrid sterility in rice is mediated by OgTPR 1 at the $\mathrm{S} 1$ locus encoding a peptidase-like protein. Mol Plant. 2017, 10 (8), 1137-1140.

91. Durr, J.; Papareddy, R.; Nakajima, K.; Gutierrez-Marcos, J. Highly efficient heritable targeted deletions of gene clusters and non-coding regulatory regions in Arabidopsis using CRISPR/Cas9. Sci. Rep. 2018, 8 (1), 1-11. 
92. Ordon, J.; Gantner, J.; Kemna, J.; Schwalgun, L.; Reschke, M.; Streubel, J.; Boch, J.; Stuttmann, J. Generation of chromosomal deletions in dicotyledonous plants employing a user-friendly genome editing toolkit. Plant J. 2017, 89 (1), 155-168.

93. Wu, R.; Lucke, M.; Jang, Y.-t.; Zhu, W.; Symeonidi, E.; Wang, C.; Fitz, J.; Xi, W.; Schwab, R.; Weigel, D. An efficient CRISPR vector toolbox for engineering large deletions in Arabidopsis thaliana. Plant Methods 2018, 14 (1), 1-9.

94. Schmidt, C.; Pacher, M.; Puchta, H. Efficient induction of heritable inversions in plant genomes using the CRISPR/Cas system. Plant J. 2019, 98 (4), 577-589.

95. Schwartz, C.; Lenderts, B.; Feigenbutz, L.; Barone, P.; Llaca, V.; Fengler, K.; Svitashev, S. CRISPR-Cas9-mediated 75.5-Mb inversion in maize. Nat. Plants 2020, 6 (12), 1427-1431.

96. Beying, N.; Schmidt, C.; Pacher, M.; Houben, A.; Puchta, H. CRISPR-Cas9mediated induction of heritable chromosomal translocations in Arabidopsis. Nat. Plants 2020, 6 (6), 638-645.

97. Pacher, M.; Schmidt-Puchta, W.; Puchta, H. Two unlinked double-strand breaks can induce reciprocal exchanges in plant genomes via homologous recombination and nonhomologous end joining. Genetics 2007, 175 (1), 21-29.

98. Schmidt, C.; Fransz, P.; Rönspies, M.; Dreissig, S.; Fuchs, J.; Heckmann, S.; Houben, A.; Puchta, H. Changing local recombination patterns in Arabidopsis by CRISPR/Cas mediated chromosome engineering. Nat. Commun. 2020, 11 (1), 1-8.

99. Zhou, H.; Liu, B.; Weeks, D. P.; Spalding, M. H.; Yang, B. Large chromosomal deletions and heritable small genetic changes induced by CRISPR/Cas9 in rice. Nucleic Acids Res. 2014, 42 (17), 10903-10914.

100. Kelliher, T.; Starr, D.; Richbourg, L.; Chintamanani, S.; Delzer, B.; Nuccio, M. L.; Green, J.; Chen, Z.; McCuiston, J.; Wang, W. MATRILINEAL, a sperm-specific phospholipase, triggers maize haploid induction. Nature 2017, 542 (7639), 105-109.

101. Sundaram Kuppu, M. R.; Marimuthu, M. P.; Li, G.; Huddleson, A.; Siddeek, M. H.; Terry, J.; Buchner, R.; Shabek, N.; Comai, L.; Britt, A. B. A variety of changes, including CRISPR/Cas9-mediated deletions, in CENH3 lead to haploid induction on outcrossing. Plant Biotechnol. J. 2020, 18 (10), 2068.

102. Liu, C.; Li, X.; Meng, D.; Zhong, Y.; Chen, C.; Dong, X.; Xu, X.; Chen, B.; Li, W.; Li, L. A 4-bp insertion at ZmPLA1 encoding a putative phospholipase A generates haploid induction in maize. Mol Plant. 2017, 10 (3), 520-522.

103. Zhong, Y.; Liu, C.; Qi, X.; Jiao, Y.; Wang, D.; Wang, Y.; Liu, Z.; Chen, C.; Chen, B.; Tian, X. Mutation of ZmDMP enhances haploid induction in maize. Nat. Plants 2019, 5 (6), 575-580. 
104. Liu, C.; Zhong, Y.; Qi, X.; Chen, M.; Liu, Z.; Chen, C.; Tian, X.; Li, J.; Jiao, Y.; Wang, D. Extension of the in vivo haploid induction system from diploid maize to hexaploid wheat. Plant Biotechnol. J. 2020, 18 (2), 316-318.

105. Yao, L.; Zhang, Y.; Liu, C.; Liu, Y.; Wang, Y.; Liang, D.; Liu, J.; Sahoo, G.; Kelliher, T. OsMATL mutation induces haploid seed formation in indica rice. Nat. Plants 2018, 4 (8), 530-533.

106. Zhang, Z.; Conner, J.; Guo, Y.; Ozias-Akins, P. Haploidy in Tobacco Induced by PsASGR-BBML Transgenes via Parthenogenesis. Genes 2020, 11 (9), 1072.

107. Okada, A.; Arndell, T.; Borisjuk, N.; Sharma, N.; Watson-Haigh, N. S.; Tucker, E. J.; Baumann, U.; Langridge, P.; Whitford, R. CRISPR/Cas9-mediated knockout of Ms1 enables the rapid generation of male-sterile hexaploid wheat lines for use in hybrid seed production. Plant Biotechnol. J. 2019, 17 (10), 1905-1913.

108. Li, J.; Wang, Z.; He, G.; Ma, L.; Deng, X. W. CRISPR/Cas9-mediated disruption of TaNP1 genes results in complete male sterility in bread wheat. J. Genet. Genomics 2020, 47 (5), 263-272.

109. Milner, M. J.; Craze, M.; Bowden, S.; Bates, R.; Wallington, E. J.; Keeling, A. Identification of genes involved in male sterility in wheat (Triticum aestivum L.) which could be used in a genic hybrid breeding system. Plant Direct 2020, 4 (3), e00201.

110. Jung, Y. J.; Kim, D. H.; Lee, H. J.; Nam, K. H.; Bae, S.; Nou, I. S.; Cho, Y.-G.; Kim, M. K.; Kang, K. K. Knockout of SIMS10 Gene (Solyc02g079810) Encoding bHLH Transcription Factor Using CRISPR/Cas9 System Confers Male Sterility Phenotype in Tomato. Plants 2020, 9 (9), 1189.

111. Li, J.; Zhang, H.; Si, X.; Tian, Y.; Chen, K.; Liu, J.; Chen, H.; Gao, C. Generation of thermosensitive male-sterile maize by targeted knockout of the ZmTMS5 gene. J. Genet. Genomics 2017, 44 (9), 465-468.

112. Teng, C.; Zhang, H.; Hammond, R.; Huang, K.; Meyers, B. C.; Walbot, V. Dicerlike 5 deficiency confers temperature-sensitive male sterility in maize. Nat. Commun. 2020, 11 (1), 1-9.

113. Ma, K.; Han, J.; Hao, Y.; Yang, Z.; Chen, J.; Liu, Y.-G.; Zhu, Q.; Chen, L. An effective strategy to establish a male sterility mutant mini-library by CRISPR/Cas9-mediated knockout of anther-specific genes in rice. J. Genet. Genomics 2019, 46 (5), 273-275.

114. Lan, S.; Guojun, D.; Yu, Z.; Guocheng, H.; Qiang, Z.; Guanglian, H.; Bo, X.; Deyong, R.; Jiang, H.; Li, Z. Rapid Creation of New Photoperiod-/Thermo-Sensitive Genic Male-Sterile Rice Materials by CRISPR/Cas9 System. Rice Sci. 2019, 26 (2), 129-132. 
115. Xuan, C.; Liu, Y.; Liu, C.; Lusuwi, L. B. T.; Fu, X.; Chen, X.; Ma, B. Identification and gene cloning of a male-sterile mutant Oswbc11 in rice. Plant Breed. 2019, 138 (3), 290-298.

116. Barman, H. N.; Sheng, Z.; Fiaz, S.; Zhong, M.; Wu, Y.; Cai, Y.; Wang, W.; Jiao, G.; Tang, S.; Wei, X. Generation of a new thermo-sensitive genic male sterile rice line by targeted mutagenesis of TMS5 gene through CRISPR/Cas9 system. BMC Plant Biol. 2019, $19(1), 1-9$.

117. Suketomo, C.; Kazama, T.; Toriyama, K. Fertility restoration of Chinese wild ricetype cytoplasmic male sterility by CRISPR/Cas9-mediated genome editing of nuclearencoded RETROGRADE-REGULATED MALE STERILITY. Plant Biotechnol. J. 2020, $20.0326 \mathrm{~b}$.

118. Basnet, R.; Hussain, N.; Shu, Q. OsDGD2 $\beta$ is the sole digalactosyldiacylglycerol synthase gene highly expressed in anther, and its mutation confers male sterility in rice. Rice 2019, 12 (1), 1-13.

119. Song, S.; Wang, T.; Li, Y.; Hu, J.; Kan, R.; Qiu, M.; Deng, Y.; Liu, P.; Zhang, L.; Dong, H. A novel strategy for creating a new system of third-generation hybrid rice technology using a cytoplasmic sterility gene and a genic male-sterile gene. Plant Biotechnol. J. 2021, 19 (2), 251.

120. Wang, K. Fixation of hybrid vigor in rice: synthetic apomixis generated by genome editing. aBIOTECH 2020, 1 (1), 15-20.

121. Henderson, S. W.; Henderson, S. T.; Goetz, M.; Koltunow, A. M. Efficient CRISPR/Cas9-mediated knockout of an endogenous PHYTOENE DESATURASE gene in T1 progeny of apomictic Hieracium enables new strategies for apomixis gene identification. Genes 2020, 11 (9), 1064.

122. Marconi, G.; Aiello, D.; Kindiger, B.; Storchi, L.; Marrone, A.; Reale, L.; Terzaroli, N.; Albertini, E. The Role of APOSTART in Switching between Sexuality and Apomixis in Poa pratensis. Genes 2020, 11 (8), 941.

123. Scheben, A.; Hojsgaard, D. Can we use gene-editing to induce apomixis in sexual plants? Genes 2020, 11 (7), 781.

124. Enciso-Rodriguez, F.; Manrique-Carpintero, N. C.; Nadakuduti, S. S.; Buell, C. R.; Zarka, D.; Douches, D. Overcoming self-incompatibility in diploid potato using CRISPRCas9. Front. Plant Sci. 2019, 10, 376.

125. Sehgal, N.; Singh, S. Progress on deciphering the molecular aspects of cell-to-cell communication in Brassica self-incompatibility response. 3 Biotech 2018, 8 (8), 1-17. 
127. Zhang, Y.; Ran, Y.; Nagy, I.; Lenk, I.; Qiu, J. L.; Asp, T.; Jensen, C. S.; Gao, C.

129. Ma, C.; Zhu, C.; Zheng, M.; Liu, M.; Zhang, D.; Liu, B.; Li, Q.; Si, J.; Ren, X.; using the endogenous tRNA-processing system. Hortic. Res. 2019, 6 (1), 1-15.

130. Ma, C.; Liu, M.; Li, Q.; Si, J.; Ren, X.; Song, H. Efficient BoPDS gene editing in cabbage by the CRISPR/Cas9 system. Hortic. Plant J. 2019, 5 (4), 164-169.

457

131. Zsögön, A.; Čermák, T.; Naves, E. R.; Notini, M. M.; Edel, K. H.; Weinl, S.; Freschi, L.; Voytas, D. F.; Kudla, J.; Peres, L. E. P. De novo domestication of wild tomato using genome editing. Nat. Biotechnol. 2018, 36 (12), 1211-1216.

132. Li, T.; Yang, X.; Yu, Y.; Si, X.; Zhai, X.; Zhang, H.; Dong, W.; Gao, C.; Xu, C. Domestication of wild tomato is accelerated by genome editing. Nat. Biotechnol. 2018, 36 (12), 1160-1163.

133. Lemmon, Z. H.; Reem, N. T.; Dalrymple, J.; Soyk, S.; Swartwood, K. E.;

Rodriguez-Leal, D.; Van Eck, J.; Lippman, Z. B. Rapid improvement of domestication traits in an orphan crop by genome editing. Nat. Plants 2018, 4 (10), 766-770.

134. Lacchini, E.; Kiegle, E.; Castellani, M.; Adam, H.; Jouannic, S.; Gregis, V.; Kater, M. M. CRISPR-mediated accelerated domestication of African rice landraces. PLoS One 2020, 15 (3), e0229782.

135. Breitler, J.-C.; Dechamp, E.; Campa, C.; Rodrigues, L. A. Z.; Guyot, R.; Marraccini, P.; Etienne, H. CRISPR/Cas9-mediated efficient targeted mutagenesis has the potential to accelerate the domestication of Coffea canephora. PLANT CELL TISS. ORG. 2018, 134 (3), 383-394.

136. Ueta, R.; Abe, C.; Watanabe, T.; Sugano, S. S.; Ishihara, R.; Ezura, H.; Osakabe, Y.; Osakabe, K. Rapid breeding of parthenocarpic tomato plants using CRISPR/Cas9. Sci. Rep. 2017, 7 (1), 1-8.

137. Čermák, T.; Baltes, N. J.; Čegan, R.; Zhang, Y.; Voytas, D. F. High-frequency, precise modification of the tomato genome. Genome Biol. 2015, 16 (1), 1-15. 
138. Li, J.; Meng, X.; Zong, Y.; Chen, K.; Zhang, H.; Liu, J.; Li, J.; Gao, C. Gene replacements and insertions in rice by intron targeting using CRISPR-Cas9. Nat. Plants 2016, 2 (10), 1-6.

139. Begemann, M. B.; Gray, B. N.; January, E.; Gordon, G. C.; He, Y.; Liu, H.; Wu, X.; Brutnell, T. P.; Mockler, T. C.; Oufattole, M. Precise insertion and guided editing of higher plant genomes using Cpf1 CRISPR nucleases. Sci. Rep. 2017, 7 (1), 1-6.

140. Li, J.-F.; Norville, J. E.; Aach, J.; McCormack, M.; Zhang, D.; Bush, J.; Church, G. M.; Sheen, J. Multiplex and homologous recombination-mediated genome editing in Arabidopsis and Nicotiana benthamiana using guide RNA and Cas9. Nat. Biotechnol. 2013, 31 (8), 688-691.

141. Xing, H.-L.; Dong, L.; Wang, Z.-P.; Zhang, H.-Y.; Han, C.-Y.; Liu, B.; Wang, X.C.; Chen, Q.-J. A CRISPR/Cas9 toolkit for multiplex genome editing in plants. BMC Plant Biol. 2014, 14 (1), 1-12.

142. Xie, K.; Minkenberg, B.; Yang, Y. Boosting CRISPR/Cas9 multiplex editing capability with the endogenous tRNA-processing system. Proc. Natl. Acad. Sci. U.S.A. 2015, 112 (11), 3570-3575.

143. Qi, W.; Zhu, T.; Tian, Z.; Li, C.; Zhang, W.; Song, R. High-efficiency CRISPR/Cas9 multiplex gene editing using the glycine tRNA-processing system-based strategy in maize. BMC Biotechnol. 2016, 16 (1), 1-8.

144. Wang, W.; Akhunova, A.; Chao, S.; Akhunov, E. Optimizing multiplex CRISPR/Cas9-based genome editing for wheat. BioRxiv 2016, 051342.

145. Zhang, Z.; Mao, Y.; Ha, S.; Liu, W.; Botella, J. R.; Zhu, J.-K. A multiplex CRISPR/Cas9 platform for fast and efficient editing of multiple genes in Arabidopsis. Plant Cell Rep. 2016, 35 (7), 1519-1533.

146. Wang, M.; Mao, Y.; Lu, Y.; Tao, X.; Zhu, J.-k. Multiplex gene editing in rice using the CRISPR-Cpf1 system. Mol Plant. 2017, 10 (7), 1011-1013.

147. Shen, L.; Hua, Y.; Fu, Y.; Li, J.; Liu, Q.; Jiao, X.; Xin, G.; Wang, J.; Wang, X.; Yan, C. Rapid generation of genetic diversity by multiplex CRISPR/Cas9 genome editing in rice. Sci. China Life Sci. 2017, 60 (5), 506-515.

148. Gao, W.; Long, L.; Tian, X.; Xu, F.; Liu, J.; Singh, P. K.; Botella, J. R.; Song, C. Genome editing in cotton with the CRISPR/Cas9 system. Front. Plant Sci. 2017, 8, 1364.

149. Minkenberg, B.; Xie, K.; Yang, Y. Discovery of rice essential genes by characterizing a CRISPR-edited mutation of closely related rice MAP kinase genes. Plant J. 2017, 89 (3), 636-648. 
150. Cody, W. B.; Scholthof, H. B.; Mirkov, T. E. Multiplexed gene editing and protein overexpression using a tobacco mosaic virus viral vector. Plant Physiol. 2017, 175 (1), 23-35.

151. Wang, M.; Mao, Y.; Lu, Y.; Wang, Z.; Tao, X.; Zhu, J. K. Multiplex gene editing in rice with simplified CRISPR-Cpf1 and CRISPR-Cas9 systems. J. Integr. Plant Biol. 2018, $60(8), 626-631$.

152. Shimatani, Z.; Fujikura, U.; Ishii, H.; Terada, R.; Nishida, K.; Kondo, A. Herbicide tolerance-assisted multiplex targeted nucleotide substitution in rice. Data Brief 2018, 20, $1325-1331$.

153. Ding, D.; Chen, K.; Chen, Y.; Li, H.; Xie, K. Engineering introns to express RNA guides for Cas9-and Cpf1-mediated multiplex genome editing. Mol Plant. 2018, 11 (4), 542552.

154. Wang, W.; Pan, Q.; He, F.; Akhunova, A.; Chao, S.; Trick, H.; Akhunov, E. Transgenerational CRISPR-Cas9 activity facilitates multiplex gene editing in allopolyploid wheat. CRISPR J. 2018, 1 (1), 65-74.

155. Li, J.; Zhang, S.; Zhang, R.; Gao, J.; Qi, Y.; Song, G.; Li, W.; Li, Y.; Li, G. Efficient multiplex genome editing by CRISPR/Cas9 in common wheat. Plant Biotechnol. J. 2020.

156. Sun, Q.; Lin, L.; Liu, D.; Wu, D.; Fang, Y.; Wu, J.; Wang, Y. CRISPR/Cas9mediated multiplex genome editing of the BnWRKY11 and BnWRKY70 Genes in Brassica napus L. Int. J. Mol. Sci. 2018, 19 (9), 2716.

157. Li, X.; Wang, Y.; Chen, S.; Tian, H.; Fu, D.; Zhu, B.; Luo, Y.; Zhu, H. Lycopene is enriched in tomato fruit by CRISPR/Cas9-mediated multiplex genome editing. Front. Plant Sci. 2018, 9, 559.

158. Hashimoto, R.; Ueta, R.; Abe, C.; Osakabe, Y.; Osakabe, K. Efficient multiplex genome editing induces precise, and self-ligated type mutations in tomato plants. Front. Plant Sci. 2018, 9, 916.

159. Li, R.; Li, R.; Li, X.; Fu, D.; Zhu, B.; Tian, H.; Luo, Y.; Zhu, H. Multiplexed CRISPR/Cas9-mediated metabolic engineering of $\gamma$-aminobutyric acid levels in Solanum lycopersicum. Plant Biotechnol. J. 2018, 16 (2), 415-427.

160. Yu, Z.; Chen, Q.; Chen, W.; Zhang, X.; Mei, F.; Zhang, P.; Zhao, M.; Wang, X.; Shi, N.; Jackson, S. Multigene editing via CRISPR/Cas9 guided by a single-sgRNA seed in Arabidopsis. J. Integr. Plant Biol. 2018, 60 (5), 376-381.

161. Zhong, Z.; Zhang, Y.; You, Q.; Tang, X.; Ren, Q.; Liu, S.; Yang, L.; Wang, Y.; Liu, X.; Liu, B. Plant genome editing using FnCpf1 and LbCpf1 nucleases at redefined and altered PAM sites. Mol Plant. 2018, 11 (7), 999-1002. 
162. Nakayasu, M.; Akiyama, R.; Lee, H. J.; Osakabe, K.; Osakabe, Y.; Watanabe, B.; Sugimoto, Y.; Umemoto, N.; Saito, K.; Muranaka, T. Generation of $\alpha$-solanine-free hairy roots of potato by CRISPR/Cas9 mediated genome editing of the St16DOX gene. Plant Physiol. Biochem. 2018, 131, 70-77.

163. Wang, Z.; Wang, S.; Li, D.; Zhang, Q.; Li, L.; Zhong, C.; Liu, Y.; Huang, H. Optimized paired-sgRNA/Cas9 cloning and expression cassette triggers high-efficiency multiplex genome editing in kiwifruit. Plant Biotechnol. J. 2018, 16 (8), 1424-1433.

164. Richter, J.; Watson, J. M.; Stasnik, P.; Borowska, M.; Neuhold, J.; Berger, M.; Stolt-Bergner, P.; Schoft, V.; Hauser, M.-T. Multiplex mutagenesis of four clustered CrRLK1L with CRISPR/Cas9 exposes their growth regulatory roles in response to metal ions. Sci. Rep. 2018, 8 (1), 1-14.

165. Gasparis, S.; Kała, M.; Przyborowski, M.; Łyżnik, L. A.; Orczyk, W.; NadolskaOrczyk, A. A simple and efficient CRISPR/Cas9 platform for induction of single and multiple, heritable mutations in barley (Hordeum vulgare L.). Plant Methods 2018, 14 (1), 114.

166. Feng, Z.; Zhang, Z.; Hua, K.; Gao, X.; Mao, Y.; Botella, J. R.; Zhu, J.-K. A highly efficient cell division-specific CRISPR/Cas9 system generates homozygous mutants for multiple genes in Arabidopsis. Int. J. Mol. Sci. 2018, 19 (12), 3925.

167. Pu, X.; Liu, L.; Li, P.; Huo, H.; Dong, X.; Xie, K.; Yang, H.; Liu, L. A CRISPR/LbCas12a-based method for highly efficient multiplex gene editing in Physcomitrella patens. Plant J. 2019, 100 (4), 863-872.

168. Xu, R.; Qin, R.; Li, H.; Li, J.; Yang, J.; Wei, P. Enhanced genome editing in rice using single transcript unit CRISPR-LbCpf1 systems. Plant Biotechnol. J. 2019, 17 (3), 553.

169. Butt, H.; Piatek, A.; Li, L.; SN Reddy, A.; M Mahfouz, M. Multiplex CRISPR mutagenesis of the serine/arginine-rich (SR) gene family in rice. Genes 2019, 10 (8), 596.

170. Malzahn, A. A.; Tang, X.; Lee, K.; Ren, Q.; Sretenovic, S.; Zhang, Y.; Chen, H.; Kang, M.; Bao, Y.; Zheng, X. Application of CRISPR-Cas12a temperature sensitivity for improved genome editing in rice, maize, and Arabidopsis. BMC Biol. 2019, 17 (1), 1-14.

171. Toda, E.; Koiso, N.; Takebayashi, A.; Ichikawa, M.; Kiba, T.; Osakabe, K.; Osakabe, Y.; Sakakibara, H.; Kato, N.; Okamoto, T. An efficient DNA-and selectablemarker-free genome-editing system using zygotes in rice. Nat. Plants 2019, 5 (4), 363-368.

172. Bernabé-Orts, J. M.; Casas-Rodrigo, I.; Minguet, E. G.; Landolfi, V.; Garcia-Carpintero, V.; Gianoglio, S.; Vázquez-Vilar, M.; Granell, A.; Orzaez, D. Assessment of Cas12a-mediated gene editing efficiency in plants. Plant Biotechnol. J. 2019, 17 (10), 1971-1984. 
173. Hui, L.; Zhao, M.; He, J.; Hu, Y.; Huo, Y.; Hao, H.; Hao, Y.; Zhu, W.; Wang, Y.; Xu, M. A simple and reliable method for creating PCR-detectable mutants in Arabidopsis with the polycistronic tRNA-gRNA CRISPR/Cas9 system. Acta Physiol. Plant. 2019, 41 (10), 1-14.

174. Jansing, J.; Sack, M.; Augustine, S. M.; Fischer, R.; Bortesi, L.

CRISPR/Cas9-mediated knockout of six glycosyltransferase genes in Nicotiana benthamiana for the production of recombinant proteins lacking $\beta-1,2$-xylose and core $\alpha-1,3$-fucose. Plant Biotechnol. J. 2019, 17 (2), 350-361.

175. Hsu, C.-T.; Cheng, Y.-J.; Yuan, Y.-H.; Hung, W.-F.; Cheng, Q.-W.; Wu, F.-H.; Lee, L.-Y.; Gelvin, S. B.; Lin, C.-S. Application of Cas12a and nCas9-activation-induced cytidine deaminase for genome editing and as a non-sexual strategy to generate homozygous/multiplex edited plants in the allotetraploid genome of tobacco. Plant Mol. Biol. 2019, 101 (4), 355-371.

176. Xiong, X.; Liu, W.; Jiang, J.; Xu, L.; Huang, L.; Cao, J. Efficient genome editing of Brassica campestris based on the CRISPR/Cas9 system. Mol. Genet. Genomics 2019, 294 (5), 1251-1261.

177. Lee, K.; Zhang, Y.; Kleinstiver, B. P.; Guo, J. A.; Aryee, M. J.; Miller, J.; Malzahn, A.; Zarecor, S.; Lawrence-Dill, C. J.; Joung, J. K. Activities and specificities of CRISPR/Cas 9 and Cas12a nucleases for targeted mutagenesis in maize. Plant Biotechnol. $J$. 2019, 17 (2), 362-372.

178. Liu, Y.; Gao, Y.; Gao, Y.; Zhang, Q. Targeted deletion of floral development genes in Arabidopsis with CRISPR/Cas9 using the RNA endoribonuclease Csy4 processing system. Hortic. Res. 2019, 6 (1), 1-10.

179. Jia, H.; Orbović, V.; Wang, N. CRISPR-LbCas12a-mediated modification of citrus. Plant Biotechnol. J. 2019, 17 (10), 1928-1937.

180. Xu, Z.-S.; Feng, K.; Xiong, A.-S. CRISPR/Cas9-mediated multiply targeted mutagenesis in orange and purple carrot plants. Mol. Biotechnol. 2019, 61 (3), 191-199.

181. Oliva, R.; Ji, C.; Atienza-Grande, G.; Huguet-Tapia, J. C.; Perez-Quintero, A.; Li, T.; Eom, J.-S.; Li, C.; Nguyen, H.; Liu, B. Broad-spectrum resistance to bacterial blight in rice using genome editing. Nat. Biotechnol. 2019, 37 (11), 1344-1350.

182. Xiong, X.; Liang, J.; Li, Z.; Gong, B. Q.; Li, J. F. Multiplex and optimization of dCas9-TV-mediated gene activation in plants. J. Integr. Plant Biol. 2020.

183. Ma, X.; Zhang, X.; Liu, H.; Li, Z. Highly efficient DNA-free plant genome editing using virally delivered CRISPR-Cas9. Nat. Plants 2020, 6 (7), 773-779. 
184. Zhang, C.; Wang, F.; Zhao, S.; Kang, G.; Song, J.; Li, L.; Yang, J. Highly efficient CRISPR-SaKKH tools for plant multiplex cytosine base editing. Crop J. 2020, 8 (3), 418 423.

185. Liu, X.; Zhou, X.; Li, K.; Wang, D.; Ding, Y.; Liu, X.; Luo, J.; Fang, C. A simple and efficient cloning system for CRISPR/Cas9-mediated genome editing in rice. PeerJ. 2020, 8 , e8491.

186. Wang, M.; Xu, Z.; Gosavi, G.; Ren, B.; Cao, Y.; Kuang, Y.; Zhou, C.; Spetz, C.; Yan, F.; Zhou, X. Targeted base editing in rice with CRISPR/ScCas9 system. Plant Biotechnol. J. 2020, 18 (8), 1645.

187. Bai, M.; Yuan, J.; Kuang, H.; Gong, P.; Li, S.; Zhang, Z.; Liu, B.; Sun, J.; Yang, M.; Yang, L. Generation of a multiplex mutagenesis population via pooled CRISPR-Cas9 in soya bean. Plant Biotechnol. J. 2020, 18 (3), 721-731.

188. Huang, X.; Wang, Y.; Xu, J.; Wang, N. Development of multiplex genome editing toolkits for citrus with high efficacy in biallelic and homozygous mutations. Plant Mol. Biol. 2020, 104 (3), 297-307.

189. Ellison, E. E.; Nagalakshmi, U.; Gamo, M. E.; Huang, P.-j.; Dinesh-Kumar, S.; Voytas, D. F. Multiplexed heritable gene editing using RNA viruses and mobile single guide RNAs. Nat. Plants 2020, 6 (6), 620-624.

190. Wolabu, T. W.; Cong, L.; Park, J.-J.; Bao, Q.; Chen, M.; Sun, J.; Xu, B.; Ge, Y.; Chai, M.; Liu, Z. Development of a highly efficient multiplex genome editing system in outcrossing tetraploid alfalfa (Medicago sativa). Front. Plant Sci. 2020, 11, 1063.

191. Li, Z.; Cheng, Q.; Gan, Z.; Hou, Z.; Zhang, Y.; Li, Y.; Li, H.; Nan, H.; Yang, C.; Chen, L. Multiplex CRISPR/Cas9-mediated knockout of soybean LNK2 advances flowering time. Crop J. 2020.

192. Wang, J.; Chen, H. A novel CRISPR/Cas9 system for efficiently generating Cas9-free multiplex mutants in Arabidopsis. aBIOTECH 2020, 1 (1), 6-14.

193. Bollier, N.; Andrade Buono, R.; Jacobs, T. B.; Nowack, M. K. Efficient simultaneous mutagenesis of multiple genes in specific plant tissues by multiplex CRISPR. Plant Biotechnol. J. 2020.

194. Oerke, E.-C. J. C. P.; Crop Protection. Elsevier Science Publishing, N. Y., NY. Estimated crop losses due to pathogens, animal pests, and weeds. 1994, 535-597. 